This item was submitted to Loughborough's Research Repository by the author.

Items in Figshare are protected by copyright, with all rights reserved, unless otherwise indicated.

\title{
Overview of porous media/metal foam application in fuel cells and solar power systems
}

\section{PLEASE CITE THE PUBLISHED VERSION}

https://doi.org/10.1016/j.rser.2018.07.032

\section{PUBLISHER}

(c) Elsevier

VERSION

AM (Accepted Manuscript)

\section{PUBLISHER STATEMENT}

This paper was accepted for publication in the journal Renewable and Sustainable Energy Reviews and the definitive published version is available at https://doi.org/10.1016/j.rser.2018.07.032

\section{LICENCE}

CC BY-NC-ND 4.0

\section{REPOSITORY RECORD}

Tan, Weng C., Lip H. Saw, Hui S. Thiam, Jin Xuan, Zuansi Cai, and Ming C. Yew. 2018. "Overview of Porous Media/metal Foam Application in Fuel Cells and Solar Power Systems". figshare.

https://hdl.handle.net/2134/35049. 


\title{
Overview of porous media/metal foam application in fuel cells and solar power systems
}

\author{
Weng Cheong Tan ${ }^{\mathrm{a}}$, Lip Huat Saw ${ }^{\mathrm{a}^{*}}$, Hui San Thiam ${ }^{\mathrm{a}}$, Jin Xuan ${ }^{\mathrm{b}}$, Zuansi Cai ${ }^{\mathrm{c}}$, Ming Chian \\ Yew $^{\mathrm{a}}$ \\ ${ }^{a}$ Lee Kong Chian Faculty of Engineering and Science, UTAR, Kajang, Malaysia - 43000. \\ ${ }^{b}$ Department of Chemical Engineering, Loughborough University, Loughborough, UK. \\ ${ }^{\mathrm{c}}$ School of Engineering and The Built Environment, Edinburgh Napier University, Edinburgh \\ EH10 5DT, UK.
}

Phone: $+603-90860288$

Fax: $\quad+603-90197062$

*E-mail address: $\underline{\text { sawlh@utar.edu.my, bernardsaw81@,yahoo.com }}$

\begin{abstract}
Fuel cells and solar energy are promising candidates for electricity generation. It is forecast that fuel cells and solar power systems will play an important role in reducing the greenhouse gas footprint and replacing fossil fuels. Therefore, the limitations of fuel cells and solar power systems, such as low efficiency, high cost, and low reliability, must be addressed appropriately to enable their full potentials. Metal foam is a new class of material that has gained immense attention due to its excellent properties suitable for a wide range of applications. Its unique characteristics distinguish it from typical solid metals. The properties of metal foam can be modified during the fabrication stage by manipulating its physical structure. The goal of this paper is to review the application of metal foam in fuel cells and solar power systems. Besides, the performance of metal foam in fuel cells and solar systems is also discussed. Metal foam has been applied to the electrodes, gas diffusion layer and flow field of fuel cells to enhance performance, especially in regard to current density and flow distribution. Furthermore, metal foam is a heat exchanger for the solar energy harvesting system to improve its efficiency. Superior performances in experimental testing allows the possibility of commercialization of metal foam products in the renewable energy field.
\end{abstract}


Keywords: renewable energy; solar energy; clean energy; porous electrode; thermal management

Word count: 14000 


\section{Introduction}

Renewable energy, such as solar, waves, geothermal and wind energy, is an energy source that will not be depleted. Using renewable energy can reduce the greenhouse gas footprint by minimizing the consumption of fossil fuels used for electricity generation. This is important to ensure a cleaner and greener environment. In addition, the European Union aims to cover full energy demands, using the renewable and sustainable energy system. This has motivated researchers to explore the application of the renewable energy field to help the European Union achieve the $100 \%$ renewable energy target [1]. However, renewable energy also faces challenges due to its low efficiency and high production cost with a low return on investment. Therefore, it is essential to reduce production costs and improve efficiency to promote renewable energy globally $[2,3]$.

Fuel cell is an electrochemical device to convert chemical energy into electrical energy. Unlike a battery, which stores the chemical energy within it, the fuel cell generates electrical energy from the chemical energy supplied at the anode and cathode. Depending on the types of fuel cells, the power density may vary with different types of reactants. Various types of fuel cells are available in the laboratory and market, such as Proton Exchange Membrane Fuel Cell (PEMFC), Microbial Fuel Cell (MFC), Phosphoric Acid Fuel Cell (PAFC), Solid Acid Fuel Cell (SAFC), Solid Oxide Fuel Cell (SOFC), Alkaline Fuel Cell (AFC), Direct Methanol Fuel Cell (DMFC), etc. The by-product of a fuel cell is environmentally friendly, which makes the fuel cell a preferable choice for the renewable energy system. The fuel cell market is growing worldwide, and by 2020 , the stationary fuel cell market is expected to reach $50 \mathrm{GW}$ [4]. To advance the commercialization of the fuel cell, different approaches have been taken to improve the existing fuel cell with the aim to reduce the cost and to improve performance through modification of the fuel cell components [5-7]. 
Solar energy is a permanent heat and light source that is emitted from the sun to the Earth. The Earth receives $\sim 170$ trillion $\mathrm{kW}$ of incoming solar radiation (insolation) at the upper atmosphere. Approximately, $47 \%$ of the energy reaches the Earth's surface. The rest is reflected back into space by clouds $(\sim 17 \%)$, absorbed by ozone, water vapor and dust $(\sim 19 \%)$, scattered by air molecules $(\sim 8 \%)$, absorbed by clouds $(\sim 4 \%)$, and reflected into space by the surface $(\sim 6 \%)[8,9]$. Solar energy is important because it is renewable energy that exists abundantly, is non-polluting and is free. The solar energy received by the Earth in one and a half hours (480 EJ) is more than the energy consumption in the year 2011 retrieved from all sources (430 EJ) [10]. Therefore, development of a solar energy harvesting system is an essential approach to promote globally renewable energy production and use to solve the issues of depletion of fossil fuels for electricity generation. Besides, solar energy can help combat global warming by reducing the dependency on fossil fuels, which emit harmful gases into the atmosphere.

There are numerous solar energy harvesting systems available in the market, such as solar chimney, solar thermal energy storage, solar heater, concentrate photovoltaic, solar receiver/collector, solar pond, photovoltaic panel, etc. Low efficiency and high cost are key factors preventing the usage of solar energy harvesting systems abundantly in generating electricity. Hence, improvement of solar energy harvesting systems, such as improving the heat transfer or cooling performance, is crucial in promoting the application of solar energy harvesting systems in the worldwide market.

Metal foam is a new class of material with excellent properties that can be applied in various applications [11]. Metal foam provides excellent mechanical properties and is lightweight, while maintaining high strength and rigidity. It also has excellent acoustic properties for sound absorption application. The complex geometry within the metal foam increases the surface area per unit volume. This is an ideal characteristic for heat transfer 
application or thermal management applications, such as heat exchangers. By varying the characteristics of metal foam, such as permeability, pore size, pores per inch (PPI), etc., the metal foam can provide a unique interaction with the fluid that flows through it and results in different observations.

There are two classes of metal foam. The first type is open cell, while the second type is a closed cell. Open cell metal foam allows the fluid to flow freely through one cell to another, and the cells are not closed. The typical open cell metal foam structure is shown in Fig. 1. The closed-cell metal foam consists of continuous cell walls, which separate one cell from another with the formation of a discrete section. The geometry of the cell is usually spherical in shape [13]. Depending on the application, different characteristics of metal foam should be chosen to meet the design requirements.

In view of the above, metal foam can bring a new dimension in renewable energy application. For example, it has been used as a gas diffusion layer, electrode or flow field in fuel cells as well as heat transfer media in solar energy harvesting systems to improve efficiency and electrical performance. Metal foam, with its excellent thermal conductivity and high solid to fluid interfacial area that enhances fluid mixing, is an ideal heat transfer candidate for solar energy harvesting systems.

Although there are many solar energy harvesting systems, not every system is suitable for metal foam. Solar chimneys, solar collectors/receivers, solar heat exchangers/heaters and thermal energy storage are solar energy harvesting systems that are appropriate for metal foam [14]. In addition, the cost of metal foam has been significantly reduced due to the advancement of manufacturing methods. For example, Alcoa (USA) introduced a new process to manufacture metal foam which could lead to the price of aluminum foam being as low as USD 5 per $\mathrm{kg}$ [11]. This new manufacturing process can greatly help to reduce the production cost, so the metal foam can be commercialized. Selection of metal foam for a 
certain application is further simplified by standardization by the agency. This will further promote the application of metal foam in the renewable energy field.

In this study, a critical review of applications of metal foam in fuel cells and solar energy harvesting systems is conducted, encompassing various types of metal foam application in fuel cells. This includes proton exchange membrane fuel cells, microbial fuel cells, direct methanol fuel cells, alkaline fuel cells and solid oxide fuel cells. Applications of metal foam in solar collectors and thermal energy storage systems are also discussed. This review not only aims to provide an overview of the performance of the metal foam in fuel cells and solar power systems, but also to provide useful insight into the future development of fuel cells and solar power systems using metal foam. In addition, the challenges associated with metal foam use in fuel cells and solar power systems are also covered in the discussion.

\section{Methodology}

Despite metal foam having been used in fuel cells and solar power systems for a number of years, the understanding of the flow field and electrical and heat transfer characteristics in such systems is very limited. This is partly due to the complicated internal geometrical structure of (the strut) metal foam. As metal foam generally exhibits a random structure, it is very difficult to obtain a general correlation to describe the characteristics of this material. Numerous studies have suggested that metal foam is suitable for various applications in automotive, aerospace and electronics industries [11]. However, there are few comprehensive reviews of the application of metal foam in the renewable energy field, especially in fuel cells and solar cells.

Hence, a review of the applications of metal foam in different components of the fuel cell system such as anode, cathode and gas diffusion layer is presented. This review not only explores the technological advantages and challenges of these applications, but also proposes approaches to overcome the limitations of these applications. In addition, key factors 
affecting the performance of these applications are identified with critical discussions of future perspectives of metal foam in the individual components of fuel cells. In addition to the fuel cell system, the applications of metal foam as a heat sink in solar power systems are also reviewed. The performance of the metal foam in solar collectors and thermal energy storage systems is examined.

\section{Fuel cell}

\subsection{Proton Exchange Membrane Fuel Cell}

The Proton Exchange Membrane Fuel Cell (PEMFC) is one of the most famous types of fuel cell available in the market, also known as Polymer Electrolyte Membrane Fuel Cell. Compared to other types of fuel cells, the PEMFC offers several advantages, such as costeffectiveness, high durability and high efficiency. The United States Department of Energy (DOE) recognized it as a potential candidate to replace the internal combustion engine in the transportation sector [14]. A PEMFC consists of bipolar plates (flow field), electrodes, catalyst, membrane and current collector as shown in Fig. 2.

The PEMFC uses hydrogen as a reactant at the anode and consumes oxygen at the cathode to generate electricity. Both reactants are harmless and abundant in quantity and can be obtained through water electrolysis. The by-product of the PEMFC is water, which is clean and harmless. As illustrated in Fig. 2, an electron travels outside the circuit and generates electricity. The cation, $\mathrm{H}^{+}$, travels through the membrane electrode assembly (MEA) and combines with the anion, $\mathrm{O}^{2-}$, to produce water. The electrochemical equations at the anode and cathode are shown below:

Anode: $\quad H_{2} \rightarrow H^{2+}+2 e^{-}$

Cathode: $\quad \frac{1}{2} O_{2}+2 e^{-} \rightarrow O^{2-}$

Overall: $\quad \mathrm{H}_{2}+\frac{1}{2} \mathrm{O}_{2} \rightarrow \mathrm{H}_{2} \mathrm{O}$ 
The bipolar plate is an important component of the fuel cell and contributes more than $70 \%$ of the fuel cell weight $[16,17]$, and more than $40 \%$ of the fuel cell's cost is attributed to it. Hence, research has been conducted on the bipolar plate to reduce its weight and improve its performance. The bipolar plate acts as the backbone of the PEMFC, current collectors and flow field for reactants. A graphite bipolar plate is commonly used in the PEMFC. Graphite is a material with good surface contact resistance and superior corrosion resistance. On the downside, the graphite bipolar plate demonstrates lower performance when compared to the metal foam bipolar plate [16-28]. It is also expensive and difficult to fabricate. The key characteristics of the bipolar plate were provided by Tawfik et al. [18]. An effective bipolar plate should have high corrosion resistance, low ohmic resistance, high surface tension of water, be lightweight, have high mechanical strength, be cost-effective, and not produce metal ions. Reddy and Kumar studied the application of metal foam as the flow field and compared it with conventionally used rectangular channels through numerical analysis [19]. In the simulation, MEA, anode, and cathode were classified as flow domain with roughly 0.4 million mesh sizes. Thermodynamics equations for the electrochemical reactions and equations for membrane properties were all defined with some assumptions made in the simulation. The SIMPLE algorithm was used to solve the momentum equations, continuity equations, species flux equations and transport equations. The study concluded that decreasing the permeability of metal foam resulted in an improvement in the fuel cell's electrical performance. The average current density is about 5943 A.m ${ }^{-2}$ when the permeability is about $10^{-6} \mathrm{~m}$ and increases to $8325 \mathrm{~A} \cdot \mathrm{m}^{-2}$ when the permeability is reduced to $10^{-11} \mathrm{~m}$. The simulation results agreed with experimental data from Kumar and Reddy in which the relationship between permeability and performance of fuel cells agreed qualitatively [20]. The experimental results showed that the improvement of the fuel cell was due to pressure drop increases across the flow field. Although lower permeability produced 
better fuel performance, it is impossible to manufacture metal foam with a permeability lower than $10^{-8} \mathrm{~m}$ because of the difficulty in machining such thin cross-sectional channels. The improvement of permeability will remain limited until a new manufacturing process is introduced.

To improve the role of metal foam on bipolar plates, other parameters are considered. Afshari et al. studied the effects of channel depth and effect of metal foam porosity numerically [21]. The current density increased with increasing metal foam porosity which, however, induced a higher pressure drop. It was observed that the porosity of metal foam in the range of 0.85 to 0.7 does not affect the temperature variation along the flow channel. This phenomenon was corroborated by Hossain and Shabani's investigation [22].

The design of the flow field of the bipolar plate is critical in determining the performance of the fuel cell. Tsai et al. studied the effects of the design of the flow field by applying metal foam as the flow distributor [23]. Five types of flow fields based on metal foam were proposed and compared with the graphite bipolar plate. A metal foam flow distributor performed better than a graphite bipolar plate. Performance can also be improved by using multiple inlets and dividing metal foam into multiple regions. This can ensure better gas distribution, which will enhance the performance further. In addition, different designs of anode housing (flow field) using aluminum foam was proposed by Wilberforce et al. [24]. Flow plate designs were investigated numerically and they concluded that open pore cellular foam performs better when compared to traditional fuel cell flow plate designs. The new design reduces dead zones, which can lead to accumulation of water that affects fuel cell performance.

Carton and Olabi conducted a numerical simulation to study the flow distribution [25]. A double channel flow plate was compared with a flow plate made from pore cellular foam material. The results showed that the distribution of oxygen and hydrogen from the inlet to 
outlet were more even when open pore cellular foam was used as flow plates. On the other side, the double channel fuel cell exhibited a poor distribution of reactants. Under the same operating conditions, the current density of the foam flow plate surged by more than $55 \%$ at $0.7 \mathrm{~V}$ compared to the double channel.

Tseng et al. investigated the effect of porosity, hydrophobic treatment and operating conditions of the metal foam flow field experimentally [26]. Metal foam performed better than the conventional graphite plate flow channel with a negligible corrosion problem. Hossain and Shabani summarized the challenges of using metal foam in the PEMFC [22]. The challenges included corrosion of the metal body, which will lead to decreasing conductivity. It is believed that metal foam is a good candidate for the PEMFC, but more experimental data are needed to validate it. Besides, existing numerical models are not yet mature. Hence, an in-depth investigation of metal foam should be conducted to make use of its unique properties for fuel cell applications. Besides this, the corrosion issues of metal foam can be balanced by applying a layer of coating. Some common coatings used are noble metals, metal oxides, metal carbides and graphite [29-31].

Temperature can affect the performance of a fuel cell. An optimum operating temperature is desirable to achieve a high-performance fuel cell. At low temperature, the rate of reactions of the fuel cell will be reduced and lead to performance losses, especially in current density. At high temperature, it will dry the membrane and reduce the ionic conductivity and the maximum theoretical voltage of a fuel cell will be affected.

In winter, it is hard to start a fuel cell, especially when the ambient temperature is below $0{ }^{\circ} \mathrm{C}$ at which temperature water freezes and causes a blockage on the cathode. It is vital to make sure the fuel cell maintains its function in winter, especially in automotive applications. Huo et al. conducted experimental studies to investigate the cold start behavior of a PEMFC using nickel foam for cathode flow distribution [27]. Under galvanostatic control, the 
performance of metal foam for cathode flow distribution is better than that of the conventional parallel flow channel. Applying metal foam results in better gas flow and improved ice storage.

The effect of high temperature on the PEMFC was investigated by Tseng et al. [28]. At high temperature, the water is not in a liquid state but in its steam phase. A fuel cell installed with metal foam performed $20 \%$ better than a graphite serpentine flow field plate at high temperature. A high temperature PEMFC (HT-PEMFC) offers benefits of higher electrochemical kinetics on the catalyst, faster rate of reaction, improved external thermal management, simplified internal water-management, and no water flooding.

A study of the PEMFC thermal management system was conducted by Odabaee et al. experimentally [32] and Afshari et al. numerically [33]. Odabaee et al. used a metal foam heat exchanger as the thermal management system for the PEMFC [32]. The water cooling system of the fuel cell was replaced with an air cooling system using aluminum metal foam. Compared to a water-cooled fuel cell system, only half of the pumping power was required for the aluminum foam to remove the same heat under the same operating conditions. Besides, the air-cooled metal foam generated more uniform temperature distribution within the graphite plate. Afshari et al. inserted cooling plates (bipolar plates) within the PEMFC stack and concluded that metal foam is able to maintain temperature uniformity with a low pressure drop [33]. This is mainly contributed by the high permeability coefficient of metal foam.

Water management is essential to ensure smooth operation of the PEMFC. Too little water will reduce the membrane's durability and lead to poor electrode adhesion on the membrane, while too much water will cause flooding at the cathode gas diffusion layer (GDL). Balancing the water content in the PEMFC is important for its operation [34]. Three main problems yet to be resolved in a conventional PEMFC membrane humidifier are the cost of machining, disturbance of water diffusion under the ribs of the channel plates, and 
additional weight and volume imposed on the channel. The above-mentioned problems can be solved by applying metal foam [35]. Using metal foam on both sides (wet and dry) can enhance performance. However, there is no improvement when using metal foam on the dry side. Besides this, lightweight metal foams can reduce the mass and provide a high surface to volume ratio that can enhance the reaction sites, which further improves the flow distribution.

An Air-breathing PEM fuel cell (ABPEM) is a new type of PEMFC, with the cathode side open to the atmosphere. The absorption of oxygen by the cathode is mainly based on the convection from its surroundings. Since it does not require an extra component to supply oxygen to the cathode, it is simpler compared to a pressurized air PEM (PAPEM). Its lightness and simple design are ideal for portability. However, it performed poorly with only $350 \mathrm{~mW} \cdot \mathrm{cm}^{-2}$ of power density produced compared to PAPEM with $566 \mathrm{~mW} \cdot \mathrm{cm}^{-2}$ [36]. To improve its efficiency, the idea to apply open pore cellular foam on the anode and cathode sides was proposed by Baroutaji et al. [37]. The findings concluded that the ABPEM has a weakness in the form of a water management problem, which can be solved by coating the PTFE on the metal foam. Compared to the work done by Jeong et al. [38], application of metal foam on the ABPEM exhibited a $77 \%$ increment of performance as compared to the conventional flow distributor ABPEM using a graphite flow field.

In summary, metal foam is widely used in the PEMFC. It can be used on various components of a fuel cell to optimize the fuel cell performance, such as GDL, thermal management system, bipolar plate, flow distributor, etc. Although metal foam brings tremendous advantages to the fuel cell, it is also associated with disadvantages, such as corrosion, hydrophobicity, and pressure drop. Future studies to address these problems are needed.

\subsection{Direct Methanol Fuel Cell}


The Direct Methanol Fuel Cell (DMFC) uses methanol as a reagent on the anode. It is well-known for its portability because methanol is in its liquid state at room temperature and its structure is simpler compared to other types of fuel cells. Although the DMFC offers higher power and energy density, the efficiency is low compared to the PEMFC. Since the DMFC is made for portability, it is lightweight. Various methods have been proposed for the DMFC, such as air-breathing and passive methanol solution supply. These designs can eliminate the parasitic power losses, as it does not require the powering of ancillary devices [39]. The operating process and structure of the DMFC are shown in Fig. 3. Electrochemical equations for the DMFC are shown in Eqs. (4) to (6).

Anode: $\quad \mathrm{CH}_{3} \mathrm{OH}+\mathrm{H}_{2} \mathrm{O} \rightarrow 6 \mathrm{H}^{+}+6 e^{-}+\mathrm{CO}_{2}$

Cathode: $\quad \frac{3}{2} \mathrm{O}_{2}+6 \mathrm{H}^{+}+6 e^{-} \rightarrow 3 \mathrm{H}_{2} \mathrm{O}$

Overall: $\quad \mathrm{CH}_{3} \mathrm{OH}+\frac{3}{2} \mathrm{O}_{2} \rightarrow 2 \mathrm{H}_{2} \mathrm{O}+\mathrm{CO}_{2}$

One drawback of the DMFC is that the methanol used in the anode contains water and methanol, which will reduce the power density of the fuel cell. Using a high concentration of methanol at the anode will cause fuel cross-over. Cross-over occurs when highly concentrated methanol diffuses through the membrane to the cathode and rapidly consumes the oxygen. Less than $30 \%$ of chemical energy in methanol can be converted to electrical energy, while the rest of the energy is converted to heat due to this phenomenon [41]. As a consequence, it is impossible to use pure methanol at the anode using current technology. Low concentration helps to hinder the diffusion rate (reduce methanol crossover) but also reduces the power density. Therefore, there should be a balance between concentrations of methanol to optimize the performance of the DMFC.

The flow field is important in the DMFC, because it helps in methanol distribution at the anode, and oxygen distribution at the cathode. As discussed, metal foam is a suitable candidate to replace graphite bipolar plates in the PEMFC. This is also applied to the DMFC 
[42-44]. Arisetty et al. examined the performance of the DMFC using metal foam as the flow

field [42]. The factors to be considered are pore size and density of the metal foam. To maintain the accuracy and consistency of the experiment, the operating condition was strictly controlled. The operating temperature was maintained at $50{ }^{\circ} \mathrm{C}$ with a constant airflow rate of $400 \mathrm{~cm}^{3} \cdot \mathrm{min}^{-1}$. The back pressure was kept at 1 bar. A methanol solution of $2 \mathrm{M}$ was used and heated to $50{ }^{\circ} \mathrm{C}$ before injection into the fuel cell. Deionized water was used to flush the fuel cell after every experiment testing to remove any residue left in the fuel cell for 15 minutes. Increasing the pore per inch (PPI) and the density of metal foam resulted in better performance, especially in current density and electrical conductivity. There will always be an obvious increase in performance when compared to a serpentine flow field. Similar to the PEMFC, the effect of corrosion is unavoidable. After 40 hours of operation, there was significant metal corrosion present in the fuel cell. A nickel coating was suggested for the metal foam to resist corrosion.

The GDL is important to ensure the fuel cell's performance by preventing flooding, maintaining humidity and ensuring an even distribution of reactants over the electrode surface. The feasibility of using metal foam as the GDL was also explored and the results showed an improvement compared to cloth and metal mesh [42]. The idea to eliminate the GDL was proposed by Chen and Zhao to reduce the weight of the DMFC [45]. New MEA was suggested by eliminating the cathode GDL and replacing it with $\mathrm{Ni}-\mathrm{Cr}$ alloy metal foam for transporting oxygen, thereby acting as a current collector. When compared to conventional MEA, this new MEA exhibited better performance and proved that application of metal foam in fuel cells is worth investing in.

Chen and Zhao also studied the possibility of using porous current collectors in passive DMFCs experimentally [39]. Ni-Cr alloy metal foam current collectors used in the passive DMFC performed better than the perforate-plate current collector. Besides this, it was more 
stable and more lightweight. Yan et al. replaced the conventional anode collector with a micro-porous anode current collector and experimented with it to investigate its performance [46]. This method can greatly reduce the effect of methanol crossover and allows more concentrated methanol to be fed to the anode. The experimental results showed that $22 \mathrm{M}$ methanol can generate a power capacity of $41.4 \mathrm{~mW} \mathrm{~cm}^{-2}$, which is $35 \%$ higher than that of the conventional DMFC.

Huang et al. studied the effect of using an anode porous catalyst layer (CL) and anode porous micro-porous layer (MPL) [47]. The porous CL and porous MPL were prepared using magnesium oxide as a sacrificial pore-former and varied with the percentage of magnesium oxide to produce a CL and MPL with different porosities. The findings concluded that the highest performance was achieved by the DMFC with a porous CL and MPL followed by the DMFC with a porous CL and the conventional DMFC. The results of the fuel cell impedance were in the opposite sequence. This proved that porous material in a CL and MPL can greatly enhance the performance of the DMFC, by increasing the catalyst utilization with a larger electrochemical surface area and reduce the charge-transfer resistance. Besides this, fuel cell performance was affected by the percentage of magnesium oxide as a pore-forming agent. When the percentage of $\mathrm{MgO}$ was increased from $0 \%$ to $20 \%$, the peak power density improved from $30 \mathrm{~mW} \mathrm{~cm}^{-2}$ to $36 \mathrm{~mW} \mathrm{~cm}^{-2}$. In addition to the anode CL, the cathode CL also plays a role in fuel cell performance. The effect of the porosity of the cathode CL was investigated by Lee et al. [48]. The porosity effect in the cathode CL contributed to the increment of fuel cell performance by $55.5 \%$, which is $11 \%$ greater than the effect of using a porous anode CL. This showed that the porosity effect is greater at the cathode and weaker at the anode. This is due to the pores in the cathode CL being more capable of removing water from the electrode and preventing flooding. 
Similar to the PEMFC, metal foam showed a positive impact when applied on the DMFC. It can be used in the CL, MPL, current collector, MEA and GDL of a DMFC. The development of metal foam on the DMFC should be continued, so the technology becomes more mature and can be commercialized, especially for portable application. It may replace the rechargeable battery due to a 5- to 10-fold improvement in energy density and having a longer cycle life [41]. The issues of methanol crossover and corrosion have yet to be resolved. Furthermore, using metal foam in MEA shows larger impedance, which is also an issue to be tackled so that cell performance can be enhanced [45].

\subsection{Microbial Fuel Cell}

The Microbial Fuel Cell (MFC) generate electricity by the aid of exoelectrogenic bacteria found in various ecological niches. Bacteria can remove organic matter from wastewater through anaerobic respiration and release electrons for electricity generation. The efficiency of the power generation depends on the type of MFC. For example, using oxidative phosphorylation can yield about $65 \%$ energy efficiency [49], while the potential efficiency is about 59\% with a high current for acetate [50]. Many advantages are associated with the MFC, such as high conversion efficiency by direct conversion of substrate energy to electricity, does not require further gas treatment of by-products, and does not require energy input for aeration given that the cathode is passively aerated and the MFC can operate at ambient or low temperatures efficiently [51]. The energy recovery rate from municipal liquid waste fraction can be improved through three stages of treatment but still requires further studies for better performance [52]. However, the MFC is limited by cost, high activation loss [53] and limited power density [54]. Factors that affect the performance of the MFC are the oxidation of substrates in an anode, permeability of PEM, and supply and consumption of oxygen in the cathode chamber. Besides, transfer of electrons from the anode compartment to anode surface is also another factor that affects the performance of the MFC [55]. To date, 
the main application of the MFC is still limited to laboratory-scale devices. It is proposed that the MFC can be used in applications, such as biosensors, biohydrogen production [56], bioelectricity generation and wastewater treatment [57].

Construction of the MFC is illustrated in Fig. 4, and it shows that bacteria tend to stick to the anode electrode and oxidation takes place to release electrons and hydrogen ion. The electrochemical equations of the MFC are rather complicated because of different microorganisms at the anode and electron acceptors at the cathode. The byproducts of the MFC reactions are water and carbon dioxide.

Some common bacteria and corresponding substrate used in the MFC are shown in Table 1. Types of substrates used with the corresponding power density are shown in Table 2. By varying the type of substrate and microbes, different power densities can be achieved.

MFC-derived bioelectrochemical cells, in particular MECs (Microbial Electrolysis Cells) were reviewed by Kumar et al. [61]. A guideline was provided to develop a microbial electrochemical cell. The startup time should be kept as low as possible. The performance of the MFC can be affected by anode potential, concentration of substrate, operating temperature and material of electrodes. Besides, Kook et al. studied the feasibility of replacing commonly used Nafion membrane with supported ionic liquid membrane (SILM) $[62,63]$. The findings concluded that the energy yield can be improved in a MFC because SILM has low electrical resistivity. This suggests that metal foam with low electrical resistivity is an ideal candidate to apply on the MFC.

Although many studies have been conducted to modify the anode to improve performance such as carbon nanotube, stainless steel, nanocomposite metal oxide, conducting polymer and graphite-based material used for anode modification, there is a lack of studies using metal foam at an anode. Using metal foam at an anode aims to provide a higher specific 
surface area and increase the coverage for attachment of bacteria, which can aid to increase performance.

Yang et al. investigated the effect of different types of metallic anode on performance [64]. The results showed that the conductivity of the anode is closely related to MFC performance. Increasing the porosity will reduce the conductivity and cause lower power performance. Hence, high porosity metal foam is not desired for the MFC. However, the limitation of using metal foam can be curbed by modifying it, as shown in the work done by Karthikeyan et al. [65]. Different types of anodes were used and compared with unmodified nickel foam. The observation proved that modified nickel foam has lower ohmic resistance than unmodified one. It was suggested that the electrode used in the MFC should have characteristics such as good electrical conductivity, low resistance, anti-corrosion, chemical stability, large surface area, high biocompatibility, and good mechanical strength and toughness for better performance [66]. From the suggested characteristics, metal foam possesses a high surface area to volume ratio, good mechanical properties, high current conductivity and low resistance, which make it suitable for the electrodes.

Jiang et al. used macroporous graphite carbon foam (MGCF) as an anode to increase the surface area and polydopamine (PDA) was coated on the MGCF to improve the biocompatibility [67]. The MFC then underwent the test to determine its performance. The findings showed that the MFC with the MGCF-PDA showed the highest performance, which yielded a power density of $1735 \mathrm{~mW} \cdot \mathrm{cm}^{-2}$ compared to the MGCF with the power density of $784 \mathrm{~mW} . \mathrm{cm}^{-2}$ and conventional carbon foam with the power density of $258 \mathrm{~mW} . \mathrm{cm}^{-2}$. The improvement was about $220 \%$ and $672 \%$ for the MFC with the MGCF-PDA and the MFC with the MGCF, respectively. This is because the MGCF provides a higher surface area for bacteria attachment, while the PDA is a coating that enhances the hydrophilicity which can further promote bacteria attachment. These two factors greatly improved the performance of 
the MFC. The feasibility of using graphene foam as an anode was also investigated. It was found that a graphene foam anode has increased electrochemical interactions and results in reducing bio-convertible substrate consumption, while maintaining a short response time [68]. This is in agreement with the work by Kwok et al. who made the observation that the flowthrough design is better than the flow-over design for a MFC with graphene aerogel as a porous electrode [69].

Cheng and $\mathrm{Wu}$ investigated the performance of an air cathode MFC when using nickel foam as the current collector, PTFE as the binder and carbon as the catalyst [70]. Linear sweep voltammetry (LSV) was used to evaluate the performance of the fuel cell. From the result, a nickel foam cathode can produce current and power density about $11 \%$ and $22 \%$ higher than that of a carbon cloth cathode. This is attributed to the fact that nickel foam has lower ohmic resistance due to its highly porous structure. The internal resistance of nickel foam is $85 \Omega$ while that of carbon cloth is $109 \Omega$. However, a platinum cathode still outperformed nickel foam when it was used as a current collector with the power density of $1320 \mathrm{~mW} . \mathrm{cm}^{-2}$ versus $1190 \pm 50 \mathrm{~mW} . \mathrm{cm}^{-2}$. On the bright side, nickel foam is only $1 / 30$ of the cost of the platinum cathode, which is very attractive for mass production.

The investigation of metal foam application on the MFC is still in its premature stage with limited experimental results [71]. Hence, it required a long time to commercialize the MFC. Although attempts have been made to achieve large application of the MFC, the results are not promising [72]. The start-up time is too long and the electrodes are prone to degradation and corrosion. Therefore, this provides a useful insight to promote the research in this area. The enhancement of the conductivity of the porous electrode is needed to improve the performance of the MFC. Replacing carbon cloth as the current collector with nickel mesh or stainless-steel mesh achieved a cost reduction, yet was able to produce a high power density $[73,74]$. 


\subsection{Solid Oxide Fuel Cell}

The Solid Oxide Fuel Cell (SOFC) is an attractive fuel cell that yields energy with high efficiency using hydrogen, hydrocarbon, syngas and biofuel without producing harmful byproducts. It can reach an efficiency as high as $60 \%$ [75] and over $80 \%$ [76] if cogeneration of waste heat is carried out. Due to its flexibility of fuel feed, it can be used in various stationary or mobile applications, such as auxiliary power units, combined heat and power units and portable power sources [77]. The structure of the SOFC consists of anode, solid electrolyte and cathode as shown in Fig. 5. The structure of the SOFC may look simple, but it is very complicated to ensure the high efficiency of a SOFC. Various components, such as current collector, bi-layer electrode and interface layer, are crucial to ensure its efficiency. The materials used and manufacturing methods of the components are keys factor in determining the efficiency of the fuel cell. Similar to other types of fuel cell, the SOFC can be stacked together to increase the electricity output. However, based on the study by Hiraiwa et al. [79], the power output of a single cell in a stack cell will reduce to $70 \%$ when compared to a single cell's performance with the variation of $\pm 3 \%$. A stack fuel cell will suffer losses but prefers to be stacked together to produce a higher power output. Fig. 6 illustrates the construction of a SOFC stack. The electrochemical equations for the SOFC are listed below [78]:

Anode reaction

i) Hydrogen : $\mathrm{H}_{2}+\mathrm{O}^{2-} \rightarrow \mathrm{H}_{2} \mathrm{O}+2 e^{-}$

ii) Hydrocarbon : $\mathrm{C}_{n} \mathrm{H}_{2 n+2}+(3 n+1) \mathrm{O}^{2-} \rightarrow n \mathrm{CO}_{2}+(n+1) \mathrm{H}_{2} \mathrm{O}+(6 n+2) e^{-}$

iii) Syngas : $\mathrm{CO}+\mathrm{O}^{2-} \rightarrow \mathrm{CO}_{2}+2 e^{-}$

Cathode reaction:

Oxygen

$$
: \frac{1}{2} O_{2}+2 e^{-} \rightarrow O^{2-}
$$

Although the SOFC offers a promising prospect for replacing fossil fuels for electricity generation, it remains limited due to some drawbacks. The main disadvantages are its high 
operating temperature and cost. It usually needs to be operated within the temperature range between $800{ }^{\circ} \mathrm{C}$ and $1000{ }^{\circ} \mathrm{C}$, which can greatly affect the reliability and durability of the fuel cell due to the failure of materials. Hence, material selection is vital to ensure fuel cell performance and lifetime. The cost of the SOFC is attributed to the material, manufacturing process and operating condition. The SOFC also suffers from sulfur poisoning [81], corrosion issues [82], and coking [81, 83], which further hinders its applications. The recent trend is to focus on developing a SOFC that can operate at low temperature and the introduction of new materials to improve performance, durability, reliability and cost.

The feasibility study of using nickel foam as anode material was conducted by Arshad et al. [84]. The experiment was performed using three types of electrolytes with and without the presence of nickel foam as an anode. All three cases tested showed nickel foam as an anode produced higher power density than fuel cells without nickel foam as an anode. The peak power density was recorded at $411 \mathrm{~mW} . \mathrm{cm}^{-2}$ using samarium doped ceria (SDC) as electrolyte and nickel foam as an anode. This proved that nickel support is a good approach to enhance fuel cell performance. Zeng et al. investigated the effects of anode porosity for the SOFC [85]. The CFD approach based on FEM is used to study the effects of porosity on thermal stress, temperature, and polarization. The investigation results suggested that it is important to control the porosity as it can cause an improvement by eliminating stress in the electrodes. Increasing porosity will reduce the von Mises stress along the main flow direction, increase the polarization of the anode and improve the diffusion coefficient.

The latest generation of the SOFC is called the metal supported cell (MSC) and the metal foam is important in determining performance. The MSC can provide excellent mechanical support to the fuel cell with a fast startup at a lower cost. However, it performs poorer than an anode supported cell (ASC) in regard to power density. The EVOLVE fuel cell is a project aimed to develop a new structure for the SOFC with a high power density. In 2013, a SOFC 
with $\mathrm{NiCrAl}$ metal foam as metal support impregnated with La-doped strontium titanate (LST) with yttria-stabilized-zirconia (YSZ) as the electrolyte was developed [76]. In 2014, an anode functional layer made of gadolinium-doped ceria LST-GDC was laminated on NiCrAl metal foam and tested as a fuel cell [75]. The power density reached $20 \mathrm{~mW} \cdot \mathrm{cm}^{-2}$ [86]. The improvement was followed by optimization of the microstructure. In 2015, the fuel cell was tested with open circuit voltage measured at $0.97 \mathrm{~V}$ at the temperature of $750{ }^{\circ} \mathrm{C}$, which was lower than the theoretical Nernst Potential [87]. The power density produced at $750{ }^{\circ} \mathrm{C}$ and $0.7 \mathrm{~V}$ using lanthanum strontium cobalt ferrite (LSCF)-CGO as a composite cathode with the mixture of $\mathrm{H}_{2}$ and $\mathrm{N}_{2}$ as fuel was $80 \mathrm{~mW} . \mathrm{cm}^{-2}$. The result was not promising and further enhancement was conducted. It was predicted that pore size and thickness of NiCrAl-LST affected the performance, and further tuning of the microstructure was carried out. The latest update from the project was Jan $31^{\text {st }}$, 2017; the power density generated by the single fuel cell was $170 \mathrm{~mW} \cdot \mathrm{cm}^{-2}$ at $0.7 \mathrm{~V}$ and $750{ }^{\circ} \mathrm{C}$ [88]. This marked the end of the project. Gondolini et al. studied the feasibility of using NiCrAl metal foam as metal support for the SOFC but integrated it with nickel-gadolinium-doped-ceria (Ni-GDC) [89]. The porosity of the NiCrAl metal foam was about $80 \%$ to ensure high permeability for the gas diffusion while maintaining adequate mechanical stability of the system. Besides this, the presence of aluminum in the foam can increase the oxidation resistance by forming aluminum oxide, which improves the durability of the fuel cell.

Understanding the microstructure of porous metal is important to determine its characteristics before applying it to the fuel cell. Masson studied the morphological modeling of the metal foam supported the SOFC configuration [90]. A 3D model was developed to estimate the transport properties, such as volume fraction of the phases, gas permeation, ionic conductivity and 3D tortuosity. The model developed was based on Pluri-Gaussian and SEM imaging. This work provided a useful insight into the effect of microstructure on the transport 
properties. Maznoy et al. synthesized porous nickel-aluminum (Ni-Al) for the MSC application through a combustion synthesis route [91]. It was suggested that the size of powdered reagent was an important factor to determine the porosity and pore size of the final product. Combustion synthesis produced a porous Ni-Al plate, which was suitable to be used as a support substrate of the SOFC. The absence of chromium in the metal foam composition was to eliminate chromium poisoning, which may eventually cause degradation to the fuel cell [92]. Maznoy et al. concluded that porous Ni-Al can be a good support in the MSC after examining the effect of porosity parameters, mechanical properties and gas permeability of the synthesized material [91]. The usage of the porous $\mathrm{Ni}-\mathrm{Al}$ alloy as metal support was also supported by other studies [93-95]. At $700{ }^{\circ} \mathrm{C}$ with humid hydrogen as fuel fed to the anode, a SOFC with deformation strengthened Ni-Al alloy foam as metal support could achieve a power density of $500 \mathrm{~mW} \cdot \mathrm{cm}^{-2}$ [93]. In addition, the power density yielded by a SOFC with compressed Ni-Al alloy foam as metal support was $550 \mathrm{~mW} . \mathrm{cm}^{-2}$ under the same operating conditions [94]. Meanwhile, the power density could reach $400 \mathrm{~mW} \cdot \mathrm{cm}^{-2}$ at $800{ }^{\circ} \mathrm{C}$ when the porous Ni-Al metal support was fabricated using self-propagating high-temperature synthesis [95]. The differences in power density obtained were explained by the different porous metal structure and different types of anode material, electrolyte and cathode.

Even though the MSC has significant advantages, it also creates a new problem for fuel cell design. The high-temperature corrosion rate of porous metal is strongly affected by the porosity level. Besides, high temperature will lead to the formation of oxide scale and increase specific area resistance. It was also found that electrical resistance is influenced by the porosity of the porous metal [96]. Hence, it is important to solve the corrosion issues in porous metal. Stange et al. studied the corrosion properties of porous alloy support for the SOFC and proposed a new method to overcome the corrosion [82]. Chromium poisoning happens when the chromium in the alloy diffuses and reacts with oxygen to form chromium 
oxide. This will reduce the electrical conductivity and cause degradation of the fuel cell. Precoating and post-coating have been proposed to enhance the resistance of metal support to oxidation and chromium poisoning. Coating of $\mathrm{La}\left(\mathrm{Mn}_{0.5} \mathrm{Co}_{0.5}\right)_{0.8}$ on the porous metal will increase conductivity, improve oxidation resistance and reduce chromium poisoning to enhance performance. Introducing manganese in the coating enhances corrosive resistance [97]. Creep of the porous metal support is another issue associated with the fuel cell that needs to be solved. Good creep resistance is needed to avoid electrolyte bending and thermal stress in the fuel cell [98]. Creep will gradually generate cracks in the electrolytes and finally cause degradation of stack integrity and result in fuel cell failure. Esposito et al. proposed an understanding of the secondary creep in the porous metal supports by developing a model using the continuum damage mechanics approach [99]. The oxide layer will significantly affect the creep behavior of the porous metal, and oxidation resistance is important. The model developed was able to estimate the time to rupture in a diffusional creep regime at low stress.

Metal foam is also used in the current collector of a SOFC. Nickel metal foam is commonly used as a current collector in the SOFC [79, 83, 100-102]. The applicability of nickel-based porous metal as the current collector was studied by Hiraiwa et al. [79, 100]. It was found that Ni-10Sn porous metal exhibits a lower area-specific resistance of $0.017 \Omega . \mathrm{cm}^{-}$ ${ }^{2}$ than pure nickel porous metal after 1,000 hours of heat treatment. Nickel-tin (Ni-Sn) porous metal produces the power density of $107 \mathrm{~mW} . \mathrm{cm}^{-2}$, comparable to platinum mesh. This is an attractive result, as it can replace platinum mesh in the SOFC, which is otherwise costly. The cost can be further reduced without compromising performance. Using Ni-Sn porous material can reduce the operating temperature to below $600{ }^{\circ} \mathrm{C}$, which is very promising for mobile application. The performance remains stable after 1,000 hours due to its excellent gas diffusion and current collecting ability. $10 \mathrm{wt} \%$ of Sn within the nickel porous metal is the 
ideal composition that gives the best performance. Pure nickel metal foam is not attractive due to its high area-specific resistance and is prone to oxidation, which causes degradation of the fuel cell.

However, applying nickel metal foam is still feasible if the appropriate coating is used on the nickel foam. For example, nickel-phosphorus coated nickel foam on the current collector is coke resistant [83]. Nickel-phosphorus was coated onto nickel foam through electroless plating. This process involved submerging the nickel foam samples into the plating solution. Next, the bubbles that formed in the foam were removed by evacuating the sample for 5 minutes. The process was continued by heating the solution to $85^{\circ} \mathrm{C}$ in a water bath and it was held for 10 to 30 minutes during the plating process. Last, deionized water was used to rinse the plated samples and left to dry in a stream of air. When testing under a syngas environment, it was found that plated nickel foam exhibited high carbon deposition resistance and remained stable when the coating contained more than $6.5 \mathrm{wt} \%$ of phosphorus. However, there was about a $247 \%$ weight gain in pure nickel foam, indicating the formation of carbon on its surface. This is because hydrogen sulfide $\left(\mathrm{H}_{2} \mathrm{~S}\right)$ in syngas can poison nickel by forming nickel sulfide [103]. This greatly reduces fuel cell performance in the long term. When comparing plated nickel foam with uncoated nickel foam, both cells generate power densities of more than $900 \mathrm{~mW} . \mathrm{cm}^{-2}$, indicating that both nickel foams can perform well. Plated nickel foam has an advantage, which is coke resistance.

The performance of plated nickel foam is comparable to gold mesh as a current collector. It is suggested that nickel-phosphorus-coated nickel foam is an ideal candidate for the current collector. Copper is also an attractive coating solution for nickel foam [101]. Copper surfacemodified nickel foam was prepared in such way that copper-coated nickel foam was heated while maintaining the weight ratio of copper and nickel in a reducing atmosphere [97]. The copper and nickel ratio was 1:2. The surface-modified nickel possessed higher coking 
resistance and mechanical stability when compared to unmodified nickel foam. The power density was $10 \%$ higher than that of the gold mesh current collector in a syngas-fed SOFC. The work was continued by Low et al. in which the composition of copper/nickel was changed to 2.5 using electrochemical plating [81]. Observations of carbon deposition were the same as in the work discussed previously, but the effect of the composition of copper and nickel on the resistance was not discussed in both papers. However, it is believed that a high copper/nickel ratio is necessary to improve the resistance to carbon deposition.

Although copper offers more advantages as a current collector, it cannot be used in a high-temperature SOFC because copper has a low melting point, is structurally unstable at high temperature and ductile [104]. Copper will lose its electrode conductivity at a temperature higher than $1073 \mathrm{~K}$. This explains why nickel will always remain the preferred choice. It is also difficult to ensure a uniform thickness of copper deposited in highly porous nickel foam.

Electrodes are important components of the SOFC. They are used for electrochemical reaction sites and facilitate gas diffusion. The most commonly used materials for anode electrodes include Ni-YSZ cement anode, fluorite anode, perovskite anode, tungsten bronze anode and pyrochlore anode materials $[78,105]$. Some of the commonly used materials for cathode electrodes include perovskite, lanthanum cobaltite and ferrite, ferro-cobaltite, lanthanum manganite, nickelate and $\mathrm{K}_{2} \mathrm{NiF}_{4}$ [106]. A porous electrode can increase reaction sites due to high porosity with a large surface area. The porous structure also enables faster and even gas diffusion, which improves the performance of a SOFC.

The application of metal foam on the electrode is still not popular nowadays. Williford and Chick studied the diffusion limitation in a porous anode [107]. It was suggested that optimization of the surface diffusion, reactive area and adsorption at the electrolyte/anode is important in determining the maximum power density of a SOFC. This can greatly enhance 
the concentration polarization and promote a triple phase boundary. Evaluation of various electrode materials for low-temperature SOFCs was conducted by Jung et al. [102]. The performance of lanthanum strontium cobaltite (LCS), porous platinum and porous nickel were compared. Among three electrodes tested, porous nickel anodes always had the lowest peak power density, independent of the temperature. On the other hand, platinum electrodes performed well when applied as cathode and anode under $400{ }^{\circ} \mathrm{C}$ but performed poorer than LSC at a temperature above $450{ }^{\circ} \mathrm{C}$ as the cathode. The operating temperature is important in affecting the performance. This shows that metal foam is not suitable to be used as electrodes for the SOFC. Nickel foam performs poorly while platinum foam is too costly to be commercialized and can provide good efficiency only under low temperatures.

In a polymer fuel cell of a fuel cell stack, platinum contributes roughly $30 \%$ of the cost [108]. LSC has the advantage of producing high performance with reduced cost. Although metal foam performs poorly as the electrode in the SOFC, it can be used in other parts of a SOFC. The feasibility of using porous nickel foam as an anode conductive layer was studied by Corbin et al. [109]. As an anode conductive layer, the coefficient of thermal expansion (CTE) matching is important, while maintaining high electrical conduction and high porosity is needed to facilitate gas transport. Nickel foam possesses all the stated characteristics for CTE matching to be improved. When $\mathrm{Ni} / \mathrm{YSZ}$ is used as an anode, pressing the nickel foam before sintering can reduce the CTE of the composite to match YSZ. High-pressed nickel foam will further enhance the electrical conductivity, which is ideal for the conductive layer. The study provides guidelines on creating a wide range of porous $\mathrm{Ni} / \mathrm{YSZ}$ composites by controlling the microstructure of the nickel foam to maximize its potential as anode conductive layers.

Based on the characteristics of the metal foam, it has high electrical conductivity, porosity, high strength and is structurally stable, which meets the material requirements of a 
SOFC. However, metal foam is susceptible to corrosion, which is unavoidable in the fuel cell environment. To counter this issue, several coatings are introduced as discussed. Using metal foam alone in a fuel cell is impossible, but using metal foam as a backbone and modifying it by various means will make it possible to be used in the SOFC.

\subsection{Alkaline Fuel Cell}

An alkaline fuel cell (AFC) is a fuel cell where the operating condition is in an alkaline medium. It is one of the oldest practical fuel cells, and was used in the U.S. Apollo space program in the mid-1960s [110]. Nowadays, the development of the AFC has drawn attention from researchers due to its high efficiency, low temperature and cheapness compared to the PEMFC. Conventional AFCs use hydrogen as fuel at the anode while consuming oxygen at the cathode to produce electricity through the redox reactions at the anode and cathode with potassium hydroxide $(\mathrm{KOH})$ as the electrolyte.

Due to the rapid development of the AFC, hydrogen is no longer the only fuel that is applicable. Fuel such as ethanol [111], glucose [112] and borohydride [113] can be fed into the anode while the electrolyte can be liquid or solid, such as an anion exchange membrane (AEM) providing the electrolyte that is maintained in an alkaline medium [114]. From the study, it was found that oxidation and reduction reactions are faster in alkaline medium than acidic medium, which contributes to the higher performance of the AFC, as it can enhance the conductivity of the AEM as well [115]. In addition, the application of cheaper metal catalysts and non-noble metals is made possible by eliminating platinum, which is expensive. The study suggested that AEM (alkaline) is more suitable than PEM (acidic) for application in a fuel cell [116]. By replacing PEM with AEM, the peak power density rose from 1.5 $\mathrm{mW} . \mathrm{cm}^{-2}$ to $20 \mathrm{~mW} . \mathrm{cm}^{-2}$ with glucose used as the fuel fed at the anode.

The state of the art in AFC structure is almost similar to the other type of fuel cell, which comprises an anode, GDL, CL, electrolyte and current collector as shown in Fig. 7. The AFC 
can be stacked to increase the output power density. The electrochemical equations of the AFC are described in Eqs. (11) to (13). Hydrogen is fed to the anode, while oxygen is supplied at the cathode:

Anode: $\quad 2 \mathrm{H}_{2}+4 \mathrm{OH}^{-} \rightarrow 4 \mathrm{H}_{2} \mathrm{O}+4 e^{-}$

Cathode: $\quad \mathrm{O}_{2}+2 \mathrm{H}_{2} \mathrm{O}+4 e^{-} \rightarrow 4 \mathrm{OH}^{-}$

Overall: $\quad 2 \mathrm{H}_{2}+\mathrm{O}_{2} \rightarrow 2 \mathrm{H}_{2} \mathrm{O}$

The electrochemical equations may differ from each other and are dependent on the type of fuel. For example, supplying glucose into the anode of the AFC may generate an intermediate product such as gluconic acid [109] and enediols [117]. The intermediate products may affect the performance of the AFC. Intermediate products reduce the electrons generated in the reaction process. One mole of glucose is able to release 24 electrons [118]. This will reduce the performance and cause wastage of the chemical energy contained in the glucose.

In the AFC, the properties of the cathode are important, and will affect the performance and durability of the AFC as reviewed by Bidault et al. [119]. It was shown that the material and manufacturing method of the cathode can affect the performance of the fuel cell. Furthermore, other issues of the AFC were also addressed. Some common problems that need to be solved are carbon dioxide effect, corrosion effect, weeping and flooding, fuel crossover, and production of carbonate, as they can all lead to the deterioration of the AFC's performance.

Since the cathode is important, development of the cathode is more aggressive than the anode. Bidault et al. presented a sizeable number of studies on the cathode of the AFC [120123]. The feasibility of using nickel foam as the cathode (and its performance) was compared to silver-coated nickel foam and nickel mesh [120]. The performances were discussed in terms of resistance, impedance, cyclic voltammogram analysis and polarization curve. From 
the result, nickel foam offers various advantages compared to nickel mesh. It is cheap, has enhanced electrochemical performance, has lower ohmic resistance, has low oxygen reduction, and has reaction charge transfer resistance. The silver coating on nickel foam is important in affecting the performance. Ohmic resistance and charge transfer resistance can be reduced when a coating of silver is applied to the nickel foam. However, there was an optimum silver coating loading which was about $11 \mathrm{mg} . \mathrm{cm}^{-2}$. High coating loading will not improve the fuel cell performance, but induce extra cost to the fabrication of the electrode. Besides this, no experimental work on power density was carried out in this study. The work was continued by incorporating the electrode with GDL [121]. An extra active layer consisting of manganese (IV) oxide deposited on the carbon black was added on the top of the GDL. The newly-integrated cathode electrode design is shown in Fig. 8.

The study suggested that $\mathrm{MnO}_{2}$ is a suitable catalyst that can improve cathode performance with high potential. The polarization curve from experiments showed that the addition of manganese dioxide on the silver-plated nickel foam can produce $132 \mathrm{~mA} . \mathrm{cm}^{-2}$ compared to silver-plated nickel foam without manganese dioxide which showed only 40 mA.cm ${ }^{-2}$ at 0.8 V. In other words, the improvement was nearly threefold. The percentage of PTFE used was important to ensure that no flooding occurred on the electrode. The ratio of PTFE to carbon black of 3:1 showed superior improvement to the performance by increasing the hydrophobicity of the electrode. The GDL also played an important role in affecting cell performance and the optimum thickness was about $0.5 \mathrm{~mm}$. Reducing the thickness can improve the oxygen permeability without causing electrolyte weeping. The performance of the fuel cell is not only limited by the type of material used for the electrode, thickness of GDL and the percentage of loading; the type of catalyst is a factor that needs to be considered. Using metal foam alone as the electrode is not enough to guarantee superior performance. 
The performance of an integrated anode electrode was also investigated by Le and Zhao using ethanol as fuel [124]. The anode electrode was combined with a catalyst and diffusion layer as a whole, with nickel foam used as a skeleton substrate coated with palladium and PTFE as a binder. An AEM was used as an electrolyte. Fig. 9 shows the comparison between conventional and integrated anode electrodes. The result showed that the performance of the newly-integrated anode can produce a peak power density of $74 \mathrm{~mW} . \mathrm{cm}^{-2}$ while conventional anodes can only generate $54 \mathrm{~mW} . \mathrm{cm}^{-2}$. This is due to the increment in mass transport of fuel, reduction in cell resistance and increment in surface area for the electrochemical sites. The amount of palladium loading was also important to the study, and it was suggested that 2.0 mg.cm ${ }^{-2}$ was the optimum loading condition for the best performance. This study also showed that the cathode is dominant in affecting the fuel cell performance. However, the development of the anode is also important, as it can contribute to the improvement of the performance. The effectiveness of manganese dioxide and palladium as the catalyst in integrated electrodes is not known and further experimental work can be conducted to compare them.

Chen et al. studied glucose fuel cells and measured their performance with silver/nickel foam as the electrode and AEM as the electrolyte [117]. Nickel foam was the base material of the electrode and was coated with silver through a simple spontaneous deposition method. At $80{ }^{\circ} \mathrm{C}$, the power density of $2.03 \mathrm{~mW} . \mathrm{cm}^{-2}$ was reached when using silver/nickel foam. The power density was higher than the pure nickel foam electrodes [125]. During the electrochemical reaction, it was observed that the color of the glucose in $\mathrm{KOH}$ tended to change from transparent to claret red, indicating the formation of enediols. The presence of enediols can further boost the performance of the fuel cell.

The feasibility of using gold/nickel foam as both anode and cathode of a glucose fuel cell with AEM as the electrolyte was studied by Chen et al. [126]. Gold is a noble metal, and it 
should be able to produce a high power density based on assumption. The simple spontaneous deposition method was used on deposit gold particles on the surface of the nickel foam. Factors such as glucose concentration, $\mathrm{KOH}$ concentration, and temperature were tested against peak power density. By maintaining the concentration of $\mathrm{KOH}$ and glucose at $6 \mathrm{M}$ and $0.5 \mathrm{M}$ respectively, the power density of $26.6 \mathrm{~mW} . \mathrm{cm}^{-2}$ was yielded at $70{ }^{\circ} \mathrm{C}$. It was higher than the reported $20 \mathrm{~mW} . \mathrm{cm}^{-2}$ from other literature, and is suitable for large-scale application [111].

Comparing both works done by Chen et al. [117, 126], it was found that gold/nickel foam can perform far superiorly to silver/nickel foam, and this indicates that gold is a better catalyst than silver. The performance of gold/nickel foam as anode and cathode electrodes was also studied by Cao et al. [113]. In this study, glucose was replaced with alkaline $\mathrm{NaBH}_{4}$ at the anode, while pure oxygen was replaced with hydrogen peroxide and a Nafion-115 membrane was used. From the SEM images, gold/nickel foam had a larger surface area than that of the nickel foam, and thus the current density obtained by gold/nickel foam was also higher. It yielded a maximum of $100 \mathrm{~mW} . \mathrm{cm}^{-2}$ in power density. These results further prove that gold is a good catalyst in improving catalytic activity, and that using metal foam alone is not enough to yield good power density. High power density generated also indicates that borohydride is a suitable fuel candidate for the AFC.

Other than nickel foam, silver is also a popular selection for electrode material. Bidault and Kucernak investigated the application of porous silver membranes as the AFC cathode electrode [122]. Impedance measurement and a polarization curve were used to examine the fuel cell's performance. The anode was fed with pure hydrogen with a $\mathrm{KOH}$ solution and the cathode remained in open air. This air-breathing AFC fuel cell was measured against power density, and it showed the value of $50 \mathrm{~mW} \cdot \mathrm{cm}^{-2}$ at $25^{\circ} \mathrm{C}$. The operation conditions allowed it to be applied for a mobile application. The power density was further improved from 15 
$\mathrm{mW} . \mathrm{cm}^{-2}$ to $65 \mathrm{~mW} . \mathrm{cm}^{-2}$ [123]. This improvement was due to the replacement of PTFE with Teflon AF and adding the catalyst manganese dioxide or platinum. The Teflon AF coating was more uniform than the PTFE and this resulted in the excellent hydrophobicity of the structure, while manganese dioxide and platinum can increase the catalytic activity of the oxygen reduction reaction. Similar to nickel foam, using a silver membrane alone is not sufficient to guarantee a high power density. The addition of a catalyst on the surface is essential for improving the output. The performances of the nickel foam versus silver membrane as the cathode electrode were not compared, and this can serve as the new direction for future study.

It was believed that manufacturing methods of the electrode can affect the fuel cell's performance. Ma and Sahai investigated the impact of the AFC electrode fabrication method [127]. Two types of fabrication methods, namely the electron beam physical vapor deposition (PVD) and the ink paste methods were used to produce palladium-coated nickel foam and palladium-coated carbon paper, giving four sets of experiment subjects. The fabricated product was used as the anode of the AFC, with Nafion 212 membrane and platinum as the cathode. Borohydride, $\mathrm{NaBH}_{4}$ in $\mathrm{NaOH}$, was used as the fuel fed at the anode. In summary, nickel foam performed better than the carbon paper. The ink paste method exhibited better performance than electron beam physical vapor deposition due to greater palladium loading. The electrode prepared using PVD had lower metal loading, and yet was able to produce high power density close to the electrode prepared using ink paste.

$\mathrm{Li}$ and $\mathrm{He}$ conducted an experiment to study the layer reduction method to fabricate palladium-coated nickel foam [128]. This method was able to avoid catalyst aggregation and also ensured a thin porous catalyst film was uniformly coated on the skeleton. Additionally, it caused improvement in the electrochemical kinetics and promoted the transportation of the reactant and electrons. Experimental results demonstrated that by using this method to 
prepare palladium/nickel foam, an increment of 1.16 times of the current density can be achieved while an enhancement of power density of about 1.03 times can be achieved when compared to the conventional design. This improvement may be attributed to growth in the electrochemical surface area and mass transport due to high permeability.

An innovative design was developed to break through the bottleneck faced by current AFCs. For instance, An et al. proposed a combination via an acid-alkaline fuel cell $[129,130]$. This new design used an alkaline medium at the anode and acidic medium at the cathode. The anode electrode was made with nickel foam coated with palladium-nickel/carbon $(\mathrm{PdNi} / \mathrm{C})$, while the cathode was carbon black coated with platinum/carbon $(\mathrm{Pt} / \mathrm{C})$. The anode and cathode were separated by a Nafion 117 membrane. $\mathrm{NaOH}$ and ethanol were used as a fuel fed to the anode while hydrogen peroxide and sulfuric acid were supplied to the cathode. The output power density reached $240 \mathrm{~mW} \cdot \mathrm{cm}^{-2}$ at $60{ }^{\circ} \mathrm{C}$ for this innovative fuel cell, which was considered the highest power density achieved in the year 2011. However, hydrogen decomposition was a problem that caused a dramatic drop in the cathode potential.

Fuel cell performance was further improved by replacing the cathode electrode with a bifunctional electrode composed of nickel-chromium foam as backbones, and deposited with gold particles [130]. The peak power density produced was $200 \mathrm{~mW} . \mathrm{cm}^{-2}$. Although the power density was $40 \mathrm{mWcm}^{-2}$ lower than the previous study, it was still higher than the conventional electrode which produced only $135 \mathrm{~mW} . \mathrm{cm}^{-2}$. The benefits of using nickelchromium metal foam coated with gold were its ability to reduce the hydrogen peroxide decomposition which can lead to severe degradation. Gold was chosen as a catalyst because gold is effective in preventing the gas evolution of hydrogen peroxide [131]. From this study, it was proven that metal foam is more suitable to be applied to the electrode than carbon black, as the porosity properties of the metal foam can enhance catalytic activity and thereby reduce transport resistance. 
Nickel foam is widely used because of its excellent properties like its lightweight quality and high porosity in 3D structures, and it is able to provide sufficient mechanical strength. Popular coatings such as palladium, gold and platinum were used as a catalyst to promote the catalytic activity. The drawback of AFCs, such as degradation, is seldom discussed. It is important to understand the degradation behavior so that improvements can be made in the future. The study of degradation was carried out by Li and Zhao [132]. Anode degradation happened after 520 hours of discharge, which caused voltage loss while AEM showed a reduction in its inherent conductivity. Thus, the factors that cause degradation and solutions to compensate for it should be proposed to improve the reliability of the fuel cell. Further work is still required to improve the performance of the Anion Exchange Membrane Fuel Cell (AEMFC) as suggested by Kucernak et al. [133]. This is because its performance is still below par as compared to the PEMFC. With similar platinum loadings, the AEMFC can only produce $0.06 \mathrm{~W} . \mathrm{cm}^{-2}$ as compared to $0.544 \mathrm{~W} . \mathrm{cm}^{-2}$ [134] and $0.41 \mathrm{~W} . \mathrm{cm}^{-2}$ [135] of the PEMFC. The weak performance may be due to the poor hydroxide conduction at the catalyst layer. The performance can be enhanced by increasing the permeability, surface area, electric conductivity of the electrode, and the catalyst layer. Undoubtedly metal foam is the most suitable candidate due to its porosity characteristics.

Understanding transport phenomena is essential in the development of the AFC. It will help researchers to understand the effects of various parameters, such as anode/cathode material, concentration or type of fuel used and design structure of components that will affect the fuel cell performance without investing heavily in the experimental setup.

\subsection{Direct Ethanol Fuel Cell}

Wang et al. experimented on the Direct Ethanol Fuel Cell (DEFC) to identify the effect of metal foam on performance [136]. Two electrodes, palladium/nickel foam and palladium/palladium film foam were used. The loading of palladium on nickel foam and 
palladium film were kept constant at $0.11 \mathrm{mg} \cdot \mathrm{cm}^{-2}$ and the results showed that palladium/nickel foam can produce an oxidation peak current density of $107.7 \mathrm{~mA} . \mathrm{cm}^{-2}$. The increment was eight times greater than that of the palladium film. Besides, palladium/nickel foam exhibited stability after 500 cycles. The performance of palladium film dropped after 500 cycles. Nickel foam is a promising electrode for the DEFC.

An and Zhao studied the transport phenomenon in the DEFC [137]. Transport phenomena in the anode, membrane, and cathode were discussed in detail. It was found that the anode diffusion layer should be kept as thin as possible for better delivery of reactants. Therefore, nickel foam was suitable to be used as a diffusion layer as it has high porosity ( $95 \%)$. Application of nickel foam as a diffusion layer was also supported by Kamarudin et al. [111]. Nickel foam can enhance the ion conductivity and reduce diffusion resistance due to its high porosity and eventually leads to high performance of the fuel cell.

An et al. developed a one-dimensional model to study the DEFC [138]. The model was used to explain the phenomenon of the fuel cell. Porosity of the diffusion layer was an important factor in affecting performance. High porosity and a thin diffusion layer will offer better performance. However, this may lead to poor mechanical properties. Yang et al. proposed two-dimensional transport models to investigate the DEFC [139]. A numerical study was conducted to validate the model. The model showed good agreement with experimental data. The model accounted for the structural design of the electrodes in affecting performance. Porosity and pore size of the metal foam can affect the performance of the fuel cell. However, there is a lack of numerical studies to understand the transport phenomenon in the DEFC.

\section{Solar power system}

\subsection{Solar Collectors/Receivers}


The solar collector is a heat exchanger in which solar energy is absorbed and converted into heat. The heat is then carried away by the fluid flow within the solar collector and heat is conducted to the user. It is used for low temperature application, such as providing heat for building, hot water and solar cooling in air conditioning processes. Various parameters, such as geometry, design, working fluid and operating conditions will affect the efficiency of a solar collector. Flat plate solar collectors are popular for low and medium heating application. The performance of a solar collector depends on how much solar energy is absorbed and how well the heat is transferred to the working fluid. Low mean temperature between the collector surface and the fluid will give better performance. The heat transfer rate should be increased to produce higher efficiency.

Sopian et al. experimented on the double-pass solar collector to evaluate the thermal performance with and without porous material $[8,140]$. Porous media were inserted into the bottom channel and the experiment was carried out using halogen lamps to mimic solar radiation. The study suggested that the thermal efficiency increased when porous media were present and was attributed to the increase of heat transfer area. Naphon conducted a numerical study of the double-pass flat plate solar air heater [141]. Porous media were inserted into the bottom channel as illustrated in Fig. 10. The numerical result was compared with the experimental work done by Sopian [8]. The result obtained for the solar air heater gave an average difference of $18.4 \%$ in the presence of porous media and $4.3 \%$ in the absence of porous media, respectively. In terms of thermal efficiency, there was an improvement of $25.9 \%$ due to the existence of porous media in the bottom channel of the solar air heater.

Heat transfer enhancement of a flat-plate solar water collector was studied with the consideration of metal foam blocks in the flow channel [142]. Streamlines, pressure drops, Nusselt numbers and temperature gradients were parameters considered in this study. A correlation of Nusselt number in terms of Reynolds number, Prandtl number and porosity of 
the metal foam was developed with $\pm 15 \%$ relative deviation. Thermal performance could be improved when the inner wall of the solar absorber was replaced with metal foam. The study was continued by performing a numerical simulation on a solar flat plate collector [143]. In this study, aluminum foam filled with paraffin was used. A finite volume approach was used to discretize the governing equation with a SIMPLEC algorithm used to solve momentum and continuity equations. Two temperature models were used for the simulation. The numerical study suggested that embedding of paraffin in the aluminum foam can affect the heat transfer and melting rate of paraffin. This will result in more uniform temperature distribution. The results were accurately predicted when using local non-thermal equilibrium assumptions. This showed that metal foam is able to enhance the performance of a solar collector and the performance can be further increased by embedding paraffin in it. The effect of the Nusselt number on metal foam in a flat plate solar collector was studied by Jouybari et al. [144]. It was shown that metal foam can increase the Nusselt number of the system.

The improvement of the solar collector's efficiency can be enhanced by using nanofluid. It was suggested that types of nanofluids, mass flow rate of nanofluids, concentration and size of nanofluids affect the efficiency of the solar collector. Using $\mathrm{Cu}-\mathrm{H}_{2} \mathrm{O}$ as nanofluid exhibited an improvement of $23.83 \%$ in terms of solar collector efficiency [145]. Furthermore, solar collector efficiency underwent improvements of $15.7 \%$ and $16.7 \%$ when $\mathrm{TiO}_{2}-\mathrm{H}_{2} \mathrm{O}$ and $\mathrm{CuO}-$ $\mathrm{H}_{2} \mathrm{O}$ were used as nanofluid, respectively [146, 147].

The application of metal foam is not only limited to the flat-plate solar collector, but extends to other types of solar collector, such as the tubular solar receiver and volumetric solar receiver. Optimized design of the tubular solar receiver using porous medium was studied numerically by Lim et al. [148]. The design point was identified to provide guidelines for manufacturing processes. Porosity, thermal conductivity and the length of the porous medium were found to be factors producing a highly efficient tubular solar receiver. Thermal 
conductivity and the porosity of porous materials were factors determining the maximum temperature of the solar collector. By combining all the design points, the outlet temperature of the tubular solar receiver was about $13{ }^{\circ} \mathrm{C}$ higher than the previous unmodified system. The performance of the porous disc enhanced receiver outweighed the performance of the tubular solar receiver in the study conducted by Reddy et al. [149]. The thermal gradient between the receiver surface and the fluid was less than the conventional tubular receiver in the case of the porous disc enhanced receiver. The efficiency of the tubular receiver was improved by Baskar et al. [150]. At a Reynolds number of 31,845, the Nusselt number for the porous disc receiver was about $70 \%$ higher than that for the tubular solar receiver.

Regarding the volumetric solar receiver, a study was conducted by Becker et al., which concluded that a proper selection of porous material properties is able to reduce or avoid the flow instability [151]. The relationship between pressure drop and ceramic foam was investigated experimentally and numerically by $\mathrm{Wu}$ et al. [152]. The results showed that the pressure drop reduced with the increase of porosity and cell size of the ceramic foam in numerical and experimental works. Ergun's equation was the most successful model for predicting the pressure drop in the porous media. However, there should be an optimum porosity when applying ceramic foam to compromise the pressure drop and strength of the material. Nickel foam was used in the volumetric solar receiver and the thermal performance and flow effects were studied by Michailidis et al. [153]. From the study, the efficiency was affected by material parameters and flow conditions. The main drawback of using nickel foam is that nickel exhibits poor resistance to hot corrosion, which is the operating condition for the volumetric solar receiver. Hence, a simple treatment method using slurry aluminization of nickel foam was proposed to create a protective oxidation resistant coating on the porous material. 
The discussion above was based on the use of the steady flow rate for the working fluid. The idea of using pulsation flow for thermal enhancement was numerically examined by Huang et al. [154]. Metal foam was attached to the absorbing plate as shown in Fig. 11. It was found that the average heat transfer enhancement factor was positively correlated with the pulsating amplitude, Reynolds number, effective conductivity ratio and reduction of porosity. The Nusselt number is dependent on the Reynolds number, porosity, pulsating frequency and oscillation amplitude of the axial inlet velocity in the pulsating flow. Pulsating flow can improve heat transfer but also introduce an additional pressure drop, which requires extra pumping power to circulate the fluid. Hence, heat transfer enhancement should be correlated with the induced pressure drop for economic consideration.

Although most of the results discussed above prove that porous metal is an ideal candidate to promote heat transfer and enhance the thermal efficiency of the solar collector, this is not true for all cases. In the case of using curved flow technology, it behaves in the opposite way [155]. The duct of curved flow technology was filled with coarse aluminum chips with the porosity of 0.1453 and the fluid produced a low exit temperature compared to the clean duct. The pressure loss caused by porous media hinders the possibility of natural circulation. Hence, an extra pump power is needed to overcome the pressure loss and overall efficiency is reduced. This experiment gave an insight into the feasibility of using porous media in the solar collector which depends on the type of solar collector, as metal foam is not suitable for all types of solar collector. Investigation and experiments should be continued to identify the feasibility of metal foam for various applications.

$\mathrm{Xu}$ et al. used different models to analyze the performance of the metal foam solar collector [156]. A modified fin analysis method was proposed for better estimation of the thermal performance. The application of different model assumptions, such as local thermal non-equilibrium (LTNE) and local thermal equilibrium (LTE) was adopted for different 
situations. For example, LTNE effect in the porous media is weakened with increasing porosity while LTE is valid for a low Darcy number. Significant differences were found when the Darcy model and Brinkman model were used for small duct scale. The differences were reduced when a large duct scale was applied. Hence, the modified fin analysis (combined fin-LTE model) helps to improve the accuracy.

In conclusion, the thermal efficiency for various solar collectors can be increased to about 60 to $70 \%$ using porous material [14]. However, studies have also shown a decrement in curve flow technology efficiency. Metal foam provides an insight into the future development of the solar collector due to its excellent thermal properties. More research shall be conducted in this field for a better understanding of its impact.

\subsection{Thermal energy storage systems}

Thermal energy storage (TES) is part of a component in the solar energy harvesting system. It is used to store solar energy captured by the solar collector for later use. The availability of sunlight depends on many factors. Solar radiation changes over time and weather. On a cloudy, hazy or rainy day, solar radiation decreases and eventually becomes zero at night. Hence, thermal energy storage is used to store the solar energy, so the energy is readily available when there is no solar radiation. To ensure the availability of energy at all times, thermal energy storage should have high thermal storage capacity with a good heat transfer rate and low response time [157]. To increase efficiency, the material used for TES should have the characteristics of high operating temperature, high thermal conductivity, high thermal absorption and high specific heat capacity [158].

Metal foam possesses characteristics suitable for TES application. Metal foam cannot be used alone in TES application and usually is used with PCM to improve the performance of TES. PCM is a type of material that stores thermal energy in terms of chemical energy through melting to maintain a constant temperature in the TES. The amount of energy that 
can be absorbed depends on the latent heat of fusion. PCM has a large space capacity and isothermal behavior during melting and is mainly used in latent thermal heat storage [159]. However, its main disadvantage is low thermal conductivity, which can be compensated for by applying embedded PCM in the metal foam.

Mesalhy et al. numerically investigated the effect of thermal conductivity of PCM embedded in the high thermal conductivity porous matrix [160]. From the study, it was shown that porosity has a positive effect on melting rate and heat transfer characteristics. Low porosity can increase the melting rate, with the drawback of slowed convection motion. Besides this, the melting rate is proportional to the thermal conductivity of the porous matrix. By combining these two effects, it was suggested to use the porous matrix with high thermal conductivity and high porosity to increase the response of PCM storage.

Xiao et al. measured the thermal conductivity of paraffin/metal foam [161]. Two types of PCM, paraffin/copper foam and paraffin/nickel foam, were used. The measurement showed that the composite paraffin PCM had higher conductivity. Paraffin/nickel foam has a thermal conductivity 3 times higher than that of pure paraffin, while paraffin/copper foam has a thermal conductivity 15 times higher than that of pure paraffin. The effect of conductivity is important as shown numerically and experimentally in the work done by Chen et al. [162]. During the melting of PCM, the structure of the metal can cause a significant impact on the heat transfer rate because the metal foam will improve the heat transfer in the solid-liquid phase, attributed to the excellent thermal conductivity of metal foam. Wu and Zhao used copper and steel alloy embedded with $\mathrm{NaNO}_{3}$ [163]. The findings suggested that the heat transfer rate was improved 2.5 times as compared to the case in which the metal foam was absent. From the study carried out by Zhao et al., the heat transfer rate was increased by 3 to 10 times when adding metal foam in the PCM [164]. The degree of improvement depends on 
the structure and material of the metal foam. The time taken for solidification of PCM was reduced by more than half when metal foam was integrated into the PCM.

The effect of melting rate in the presence of metal foam was investigated numerically by Yang et al. [165]. A tetrakaidecahedron unit cell was used to mimic real foam application in the study. It was found that metal foam can accelerate the melting rate of PCM. The melting time was $37.5 \%$ lower compared to the case without metal foam. This showed that the response time had been reduced and the efficiency of the TES had been increased. The numerical result agreed with the experimental result from Badenhorst et al. [166]. In this study, graphite foam was used for storage of concentrated solar energy and solar energy capture. The prototype of the solar concentrator was designed with a simple two-axis tracking method as shown in Fig. 12. The prototype was cheap and simple, yet able to reach concentration ratios in excess of 1,000 suns. Graphite foam reduced the melting time of PCM by $46 \%$ when compared to pure PCM. By manipulating the foam geometry and concentration ratio, the size of the receiver can be reduced by $75 \%$ and still provide the same efficiency.

By using different types of PCM with different types of metal foam, it greatly enhances the TES efficiency in terms of response time and the heat transfer rate. The degree of improvement depends on the types of metal foam and its properties. Proper study of PCM and metal foam characteristics can help identify the combination of PCM and metal foam that should be used for a given application. The selection of suitable PCM for a certain application is a complicated process, and a study was carried out by $\mathrm{Xu}$ et al. to help in the selection of PCM for solar absorption cooling application [167]. The method helped to identify the most suitable PCM material for a specific application. As suggested by Rashidi et al., future study is needed, especially research on the high temperature thermal energy storage system as it is limited [9].

\section{Current perspective}


Fuel cells and solar power systems are promising renewable sources that can replace fossil fuels in the future. The research in these two fields is ongoing and it can be foreseen that the performance of the fuel cell and solar power system will be increased in the near future. Metal foam with its excellent properties can improve the performance of fuel cells and solar energy power systems. Applying metal foam in both systems will improve the energy output, increase the waste heat rejection and stimulate a uniform flow field. The common issue faced by both applications is temperature control. Metal foam with its good thermal properties can enhance the heat rejection rate of the system to prolong the cycle life.

Most of the literature review is based on the performance of a single component but not a whole system and the experimental results are based on the laboratory environment. Hence, the main focus of the upcoming research should be on evaluating the performance of the fuel cell system and solar power system as a whole with metal foam components. The characteristics of metal foam are affected by pore density, porosity, permeability and interfacial area. The understanding of how these parameters affect the performance of the systems is necessary and not yet available in the literature.

Although the power density of the fuel cell can be improved by using metal foam electrodes, it also introduces serious corrosion issues. This will cause damage to the system in long-term operation. Hence, an anti-corrosion coating is needed for the metal foam. Coating methods required are far more complicated due to the presence of porosity in the metal foam. Besides, it is also necessary to ensure that the internal surface of the pores receives sufficient coating as compared to the outer metal foam surface. Other issues such as fuel crossover, high impedance of the fuel cell, hydrophobicity and pressure drop are interesting topics of concern as well.

There are many types of porous media available in the market with different pore density, porosity and material. Most of the studies are focused on a single characteristic of the metal 
foam. For example, the application of metal foam in the fuel cell is focused on nickel foam only but other types of porous media are rarely investigated. Besides, study of the effect of using different combinations of porosity and pore density in a system is also very rare. On the other hand, the application of porous media in the solar energy harvesting system is relatively new and has not been applied in commercial products. This could provide a future direction of metal foam research in the renewable energy field especially in the fuel cell and solar power system.

\section{Conclusions}

Numerous experiments and numerical simulations have been conducted to study the application of metal foam on the fuel cell and solar energy harvesting system. It is concluded that metal foam is a promising material to be implemented in a fuel cell and solar energy harvesting system. It can boost performance and provide additional benefits, such as reduced cost and overall weight. In a fuel cell system, using metal foam alone as a component is not satisfactory. Metal foam is not corrosion resistant, is subject to carbon deposition at high temperature and is not hydrophobic. Hence, a coating is necessary to minimize the corrosion issue of metal foam. Besides, the coating also helps to prevent carbon deposition and repel water. The electrical characteristics can be further improved with a coating of metal foam. In the solar energy harvesting system, metal foam can be modified to enhance thermal performance, such as embedding paraffin into the metal foam. Most literature suggests nickel foam to be well-suited for fuel cell application, while there is no consensus on the types of metal foam to be used in the solar energy harvesting system. This can provide a new direction for future study. In addition, there are limited numerical studies that identify the relationship between the characteristics of metal foam and performance. Forthcoming studies can focus on developing porous media models to form a set of correlation equations. The equations can help predict the performance by manipulating the characteristics of the metal foam. This is 
important, as it can greatly reduce the experimental time and cost of producing a prototype for experimental study.

\section{Acknowledgements}

This work is supported by UTARRF Grant No. IPSR/RMC/UTARRF/2016-C1/T8 and Science fund Grant No. 03-02-11-SF0216 from the Ministry of Science, Technology and Innovation, Malaysia.

The authors would like to thank Elsevier for the permission of using Fig. 1 as in ref [12], Fig. 5 as in ref [78], Fig. 8 as in ref [121], Fig. 9 as in ref [124], Fig 10, as in ref [8], Fig. 11 as in ref [142], Fig. 12 as in ref [166], Table 1 as in ref [59] and Table 2 as in ref [60].

The authors would like to thank the fuel economy as in ref [15] for the permission of using Fig. 2.

The authors would like to thank the Earth Science Australia as in ref [40] for the permission of using Fig. 3 and Fig. 7.

The authors would like to thank the author as in ref [58] for the permission of using Fig. 4.

The authors would like to thank Springer-Verlag for the permission of using Fig. 6 as in ref $[80]$. 


\section{References:}

[1] Olabi AG. Energy quadrilemma and the future of renewable energy. Appl Energy 2016;108:1-6.

[2] Saw LH, Ye Y, Tay AAO. Integration issues of Lithium-ion battery into battery pack for electric vehicles. J Clean Prod 2016;113:1032-1045.

[3] Saw LH, Ye Y, Tay AAO. Electro-thermal analysis and integration issues of Lithiumion battery for electric vehicles. Appl Energ 2014;131:97-107.

[4] Prabhu RR. Stationary Fuel Cells Market size to reach 350,000 Shipments by 2022. Renew India Campaign, http://www.renewindians.com/2013/01/stationary-fuel-cellsmarket-size-to-reach-350000-shipments-by-2022.html; 2013 [accessed 15 August 2017].

[5] Thiam HS, Daud WRW, Kamarudin SK, Mohamad AB, Kadhum AAH, Loh KS, Majlan EH. Overview on nanostructured membrane in fuel cell applications. Int $\mathbf{J}$ Hydrog Energ 2011;36:3187-3205.

[6] Thiam HS, Daud WRW, Kamarudin SK, Mohamad AB, Kadhum AAH, Loh KS, Majlan EH. Nafion/Pd-SiO ${ }_{2}$ nanofiber composite membranes for direct methanol fuel cell applications. Int J Hydrog Energ 2011;38:9474-9483.

[7] Thiam HS, Daud WRW, Kamarudin SK, Mohamad AB, Kadhum AAH, Loh KS, Majlan EH. Performance of direct methanol fuel cell with a palladium-silica nanofibre/Nafion composite membrane. Energy Convers Manag 2013;75:718-726.

[8] Sopian K, Supranto, Daud WRW, Othman MY, Yatim B. Thermal performance of the double-pass solar collector with and without porous media. Renew Energy 1999; 18:557-64.

[9] Basic of Solar energy. The electronic universe, http://zebu.uoregon.edu/disted/ph162/14.html; 2011[accessed 20 Sept 2017].

[10] Jeff T, Nate L, George C. Solar FAQs. Sandia National Laboratory, http://www.sandia.gov/ jytsao/Solar FAQs.pdf; 2006 [accessed 20 Sept 2017].

[11] Lefebvre L-P, Banhart J, Dunand DC. Porous Metals and Metallic Foams: Current Status and Recent Developments. Adv Eng Mater 2008;10:775-87.

[12] Saw LH, Ye Y, Yew MC, Chong WT, Yew MK, Ng TC. Computational fluid dynamics simulation on open cell aluminium foams for Li-ion battery cooling system. Appl Energy 2017;204:1489-1499.

[13] Ashby MF, Evans A, Fleck NA, Gibson LJ, Hutchinson JW, Wadley HNG. Metal Foams: A Design Guide. Met. Foam. A Des. Guid. 1st ed., Butterworth-Heinemann; 2000, p. 181-8. 
[14] Rashidi S, Esfahani JA, Rashidi A. A review on the applications of porous materials in solar energy systems. Renew Sustain Energy Rev 2017;73:1198-210.

[15] Fuel economy. How Fuel Cells Work, https://www.fueleconomy.gov/feg/fcv_PEM.shtml [accessed August 20, 2017].

[16] Chang HP, Chou CL, Chen YS, Hou TI, Weng BJ. The design and cost analysis of a portable PEMFC UPS system. Int J Hydrogen Energy 2007;32:316-22.

[17] Afshari E, Jazayeri SA. Effects of the cell thermal behavior and water phase change on a proton exchange membrane fuel cell performance. Energy Convers Manag 2010;51:655-62.

[18] Tawfik H, Hung Y, Mahajan D. Metal bipolar plates for PEM fuel cell-A review. J Power Sources 2007;163:755-67.

[19] Kumar A, Reddy RG. Modeling of polymer electrolyte membrane fuel cell with metal foam in the flow-field of the bipolar/end plates. J Power Sources 2003;114:54-62.

[20] Kumar A, Reddy RG. Materials and design development for bipolar/end plates in fuel cells. J. Power Sources 2004;129:62-7.

[21] Afshari E, Mosharaf-Dehkordi M, Rajabian H. An investigation of the PEM fuel cells performance with partially restricted cathode flow channels and metal foam as a flow distributor. Energy 2017;118:705-15.

[22] Hossain MS, Shabani B. Metal foams application to enhance cooling of open cathode polymer electrolyte membrane fuel cells. J Power Sources 2015;295:275-91

[23] Tsai BT, Tseng CJ, Liu ZS, Wang CH, Lee CI, Yang CC, Lo SL. Effects of flow field design on the performance of a PEM fuel cell with metal foam as the flow distributor. Int J Hydrogen Energy 2012;37:13060-6.

[24] Wilberforce T, Makky AA, Baroutaji A, Sambi R, Olabi AG. Computational Fluid Dynamic simulation and modelling (CFX) of flow plate in PEM fuel cell using aluminum open cellular foam material. 2017 IEEE Texas Power Energy Conf 2017:16.

[25] Carton JG, Olabi AG. Three-dimensional proton exchange membrane fuel cell model: Comparison of double channel and open pore cellular foam flow plates. Energy 2017;136:185-95.

[26] Tseng CJ, Tsai BT, Liu ZS, Cheng TC, Chang WC, Lo SK. A PEM fuel cell with metal foam as flow distributor. Energy Convers Manag 2012;62:14-21.

[27] Huo S, Cooper NJ, Smith TL, Park JW, Jiao K. Experimental investigation on PEM fuel cell cold start behavior containing porous metal foam as cathode flow distributor. Appl Energy 2017;203:101-14. 
[28] Tseng CJ, Heush YJ, Chiang CJ, Lee YH, Lee KR. Application of metal foams to high temperature PEM fuel cells. Int J Hydrogen Energy 2016;41:16196-204.

[29] Hung Y, El-Khatib KM, Tawfik H. Testing and evaluation of aluminum coated bipolar plates of pem fuel cells operating at $70^{\circ} \mathrm{C}$. J Power Sources 2006;163:509-13.

[30] Wang WL, He SM, Lan CH. Protective graphite coating on metallic bipolar plates for PEMFC applications. Electrochim Acta 2012;62:30-5.

[31] Wang Y, Northwood DO. An investigation into TiN-coated 316L stainless steel as a bipolar plate material for PEM fuel cells. J Power Sources 2007;165:293-8.

[32] Odabaee M, Mancin S, Hooman K. Metal foam heat exchangers for thermal management of fuel cell systems - An experimental study. Exp Therm Fluid Sci 2013;51:214-9.

[33] Afshari E, Ziaei-Rad M, Shariati Z. A study on using metal foam as coolant fluid distributor in the polymer electrolyte membrane fuel cell. Int J Hydrogen Energy 2016;41:1902-12.

[34] Ji M, Wei Z. A review of water management in polymer electrolyte membrane fuel cells. Energies 2009;2:1057-106.

[35] Afshari E, Baharlou Houreh N. Performance analysis of a membrane humidifier containing porous metal foam as flow distributor in a PEM fuel cell system. Energy Convers Manag 2014;88:612-21.

[36] Ous T, Arcoumanis C. The formation of water droplets in an air-breathing PEMFC. Int J Hydrogen Energy 2009;34:3476-87.

[37] Baroutaji A, Carton JG, Stokes J, Olabi AG. Application of Open Pore Cellular Foam for air breathing PEM fuel cell. Int J Hydrogen Energy 2017;42:25630-8.

[38] Jeong SU, Cho EA, Kim HJ, Lim TH, Oh IH, Kim SH. Effects of cathode open area and relative humidity on the performance of air-breathing polymer electrolyte membrane fuel cells. J Power Sources 2006;158:348-53.

[39] Chen R, Zhao TS. Porous current collectors for passive direct methanol fuel cells. Electrochim Acta 2007;52:4317-24.

[40] Earth Science Australia. Fuel Cells, http://earthsci.org/mineral/energy/fuelcell/fuelcell.html\#TOP [accessed August 20, 2017].

[41] Kamarudin SK, Achmad F, Daud WRW. Overview on the application of direct methanol fuel cell (DMFC) for portable electronic devices. Int J Hydrogen Energy 2009;34:6902-16.

[42] Arisetty S, Prasad AK, Advani SG. Metal foams as flow field and gas diffusion layer in direct methanol fuel cells. J Power Sources 2007;165:49-57. 
[43] Jiang R, Rong C, Chu D. Determination of energy efficiency for a direct methanol fuel cell stack by a fuel circulation method. J Power Sources 2004;126:119-24.

[44] Arisetty S, Advani SG, Prasad AK. Methanol diffusion rates through the anode diffusion layer in direct methanol fuel cells from limiting current measurements. Heat Mass Transf 2008;44:1199-206.

[45] Chen R, Zhao TS. A novel electrode architecture for passive direct methanol fuel cells. Electrochem Commun 2007;9:718-24.

[46] Yan XH, Zhao TS, An L, Zhao G, Zeng L. A micro-porous current collector enabling passive direct methanol fuel cells to operate with highly concentrated fuel. Electrochim Acta 2014;139:7-12.

[47] Huang Q, Jiang J, Chai J, Yuan T, Zhang H, Zou Z, Zhang X, Yang H. Construction of porous anode by sacrificial template for a passive direct methanol fuel cell. J Power Sources 2014;262:213-8.

[48] Lee Y, Kim TK, Choi YS. Effect of porosity in catalyst layers on direct methanol fuel cell performances. Fuel Cells 2013;13:173-80.

[49] Rabaey K, Lissens G, Siciliano SD, Verstraete W. A microbial fuel cell capable of converting glucose to electricity at high rate and efficiency. Biotechnol Lett 2003;25:1531-5.

[50] Lee HS, Parameswaran P, Kato-Marcus A, Torres CI, Rittmann BE. Evaluation of energy-conversion efficiencies in microbial fuel cells (MFCs) utilizing fermentable and non-fermentable substrates. Water Res 2008;42:1501-10.

[51] Rabaey K, Verstraete W. Microbial fuel cells: Novel biotechnology for energy generation. Trends Biotechnol 2005;23:291-8.

[52] Rozsenberszki T, Kook L, Bakonyi P, Nemestothy N, Logrono W, Perez M, Urquizo G, Recalde C, Kurdi R, Sarkady A. Municipal waste liquor treatment via bioelectrochemical and fermentation $\left(\mathrm{H}_{2}+\mathrm{CH}_{4}\right)$ processes: Assessment of various technologival sequences. Chemosphere 2017;171:692-701.

[53] Pham TH, Rabaey K, Aelterman P, Clauwaert P, De Schamphelaire L, Boon N, Verstraete W. Microbial fuel cells in relation to conventional anaerobic digestion technology. Eng Life Sci 2006;6:285-92.

[54] Hindatu Y, Annuar MSM, Gumel AM. Mini-review: Anode modification for improved performance of microbial fuel cell. Renew Sustain Energy Rev 2017;73:236-48.

[55] Rahimnejad M, Ghoreyshi AA, Najafpour G, Jafary T. Power generation from organic substrate in batch and continuous flow microbial fuel cell operations. Appl Energy 2011;88:3999-4004. 
[56] Bakonyi P, Kumar G, Kook L, Toth G, Rozsenberszki T, Belafi-Bako K, Nemestothy N. Microbial electrohydrogenesis linked to dark fermentation as integrated application for enhanced biohydrogen production: A review on process characteristics, experiences and lessons. Bioresource Technology 2018;251:381-389.

[57] Rahimnejad M, Adhami A, Darvari S, Zirepour A, Oh SE. Microbial fuel cell as new technology for bioelectricity generation: A review. Alexandria Eng J 2015;54:745-56.

[58] Parkash A. Microbial Fuel Cells: A Source of Bioenergy. J Microb Biochem Technol 2016;8:247-255.

[59] Du Z, Li H, Gu T. A state of the art review on microbial fuel cells: A promising technology for wastewater treatment and bioenergy. Biotechnology Advances 2007;25:464-482.

[60] Pant D, Bogaert GV, Diels L, Vanbroekhoven K. A review of the substrates used in microbial fuel cells (MFCs) for sustainable energy production. Bioresource Technology 2010;101:1533-1543.

[61] Kumar G, Bakonyi P, Zhen G, Sivagurunathan P, Kook L, Kim SH, Toth G, Nemestothy N, Belafi-Bako K. Microbial electrochemical systems for sustainable biohydrogen production: Surveying the experiences from a start-up viewpoint. Renew Sustain Energy Rev 2017;70:589-597.

[62] Kook L, Nemestothy N, Bakonyi P, zhen G, Kumar G, Lu X, Su L, Saratale GD, Kim $\mathrm{SH}$, Gubicza L. Performance evaluation of microbial electrochemical systems operated with Nafion and supported ionic liquid membranes. Chemosphere 2017; 175:350-355.

[63] Kook L, Nemestothy N, Bakonyi P, Gollei A, Rozsenberszki T, Takacs P, Salekovics A, Kumar G, Belafi-Bako K. On the efficiency of dual chamber biocatalytic electrochemical cells applying membrane separators prepared with imidazolium-type ionic liquids containing $\left[\mathrm{NTf}_{2}\right]^{-}$and $\left[\mathrm{PF}_{6}\right]^{-}$anions. Chem Eng J 2017;324:296-302.

[64] Yang YC, Chen CC, Huang CS, Wang CT, Ong HC. Developments of metallic anodes with various compositions and surfaces for the microbial fuel cells. Int $\mathrm{J}$ Hydrogen Energy 2017;42:22235-42.

[65] Karthikeyan R, Krishnaraj N, Selvam A, Wong JWC, Lee PKH, Leung MKH, Berchmans S. Effect of composites based nickel foam anode in microbial fuel cell using Acetobacter aceti and Gluconobacter roseus as a biocatalysts. Bioresour Technol 2016;217:113-20.

[66] Uzoma AH, Ekwutosi OT, Onyeka AC. Comparative Study of Effects of Electrode Materials and Catholyte on Simultaneous Generation of Bioelectricity and Waste water Treatment. Int J of Bioorganic Chemistry 2016;1:8-20.

[67] Jiang H, Yang L, Deng W, Tan Y, Xie Q. Macroporous graphitic carbon foam decorated with polydopamine as a high-performance anode for microbial fuel cell. J Power Sources 2017;363:27-33. 
[68] Jiang H, Ali MA, Xu Z, Halverson LJ, Dong L. Integrated Microfluidic FlowThrough Microbial Fuel Cells. Sci Rep 2017;7:41208.

[69] Kwok YH, Tsang ACH, Wang Y, Leung DYC. Ultra-fine Pt nanoparticles on graphene aerogel as a porous electrode with high stability for microfluidic methanol fuel cell. J Power Sources 2017;349:75-83.

[70] Cheng S, Wu J. Air-cathode preparation with activated carbon as catalyst, PTFE as binder and nickel foam as current collector for microbial fuel cells. Bioelectrochemistry 2013;92:22-6.

[71] Zhen G, Lu X, Kumar G, Bakonyi P, Xu K, Zhao Y. Microbial electrolysis cell platform for simulations waste biorefinery and clean electrofuels generation: Current situation, challenges and future perspectives. Prog Energy Combust Sci 2017;63:119145.

[72] Wang Q, Dong H, Yu H, Yu H, Liu M. Enhanced electrochemical reduction of carbon dioxide to formic acid using a two-layer gas diffusion electrode in a microbial electrolysis cell. RSC Adv 2015;5:10346-10351.

[73] Zhang F, Cheng S, Pant D, Bogaert G Van, Logan BE. Power generation using an activated carbon and metal mesh cathode in a microbial fuel cell. Electrochem Commun 2009;11:2177-9.

[74] Zhang F, Saito T, Cheng S, Hickner MA, Logan BE. Microbial fuel cell cathodes with poly(dimethylsiloxane) diffusion layers constructed around stainless steel mesh current collectors. Environ Sci Technol 2010;44:1490-5.

[75] Taroco HA, Santos JAF, Domingues RZ, Matencio T. Ceramic Materials for Solid Oxide Fuel Cells. In: Sikalidis C, editor. Adv. Ceram. - Synth. Charact. Process. Specif. Appl., Rijeka: InTech; 2011.

[76] Costa R, Ansar A. Evolved Materials and Innovative Design for High Performance, Durable and Reliable SOFC Cell and Stack Presentation and Status of the European Project EVOLVE. ECS Trans 2013;57:533-41.

[77] Shao Z, Tadé MO. Application of SOFC Technology. Intermed. Solid Oxide Fuel Cells, Springer, Berlin, Heidelberg; 2016, p. 247-66.

[78] Sun C, Stimming U. Recent anode advances in solid oxide fuel cells. J Power Sources 2007;171:247-60.

[79] Hiraiwa C, Okuno K, Tawarayama H, Majima M, Nishimura J, Tsuchida H. Application of Ni porous metal to solid oxide fuel cells. SEI Tech Rev 2016.

[80] Zuo C, Liu M, Liu M. Solid oxide fuel cells. In: Aparicio M, Jitianu A, Klein, LC, editors. Sol-gel processing for conventional and alternative energy, New York: Springer-Verlag; 2012, p. 7-36. 
[81] Low QX, Huang W, Fu XZ, Melnik J, Luo JL, Chuang KT, Sanger AR. Copper coated nickel foam as current collector for H2S-containing syngas solid oxide fuel cells. Appl Surf Sci 2011;258:1014-20.

[82] Stange M, Denonville C, Larring Y, Brevet A, Montani A, Sicardy O, Mougin J, Larsson PO. Improvement of corrosion properties of porous alloy supports for solid oxide fuel cells. Int J Hydrogen Energy 2017;42:12485-95.

[83] Yan N, Fu XZ, Luo JL, Chuang KT, Sanger AR. Ni-P coated Ni foam as coking resistant current collector for solid oxide fuel cells fed by syngas. J Power Sources 2012;198:164-9.

[84] Arshad MS, Mushtaq N, Ahmad MA, Naseem S, Atiq S, Ahmed Z, Ali R, Abbas G, Raza R. Nickel foam anode-supported solid oxide fuel cells with composite electrolytes. Int J Hydrogen Energy 2017;42:22288-93.

[85] Zeng S, Xu M, Parbey J, Yu G, Andersson M, Li Q, Li B, Li T. Thermal stress analysis of a planar anode-supported solid oxide fuel cell: Effects of anode porosity. Int J Hydrogen Energy 2017;42:20239-48

[86] Costa R, Ansar A. Progress in the development of Nickel-less SOFCs: status of the EU project EVOLVE. 11 th Eur SOFC SOE Forum 2014:B0150.

[87] Han F, Semerad R, Constantin G, Dessemond L, Costa R. Beyond the 3rd Generation of Planar SOFC: Development of Metal Foam Supported Cells with Thin Film Electrolyte. ECS Trans Electrochem Soc 2015;68:1889-96.

[88] Project finalize!. Evolve fuel cell, http://www.evolvefcell.eu/index.php/newsreader/items/project-completion-by-the-31st-of-january2017.html; 2017 [accessed 1 Oct 2017].

[89] Gondolini A, Mercadelli E, Sangiorgi A, Sanson A. Integration of Ni-GDC layer on a NiCrAl metal foam for SOFC application. J Eur Ceram Soc 2017;37:1023-30.

[90] Masson D, Abdallah B, Willot F, Jeulin D, Mercadelli E, Sanson A, Chesnaud A, Thorel A. Morphological Modelling of a Metal Foam Supported SOFC Configuration. ECS Trans 2015;68:2951-60.

[91] Maznoy A, Kirdyashkin A, Kitler V, Solovyev A. Combustion synthesis and characterization of porous $\mathrm{Ni}-\mathrm{Al}$ materials for metal-supported solid oxide fuel cells application. J Alloys Compd 2017;697:114-23

[92] Matsuzaki Y, Yasuda I. Dependence of SOFC Cathode Degradation by ChromiumContaining Alloy on Compositions of Electrodes and Electrolytes. J Electrochem Soc 2001;148:A126.

[93] Sadykov VA, Usoltsev V V, Fedorova YE, Sobyanin VA, Kalinin P V, Arzhannikov A V, Vlasov AY, Korobeinikov MV, Bryazgin AA, Salanov AN, Predtechenskii MR, Bobrenok OF, Ulikhin AS, Uvarov NF, Smorygo OL, Il'yushchenko AF, Ul'yanitskii VY, Zlobin SB. Design of Medium-Temperature Solid Oxide Fuel Cells on Porous 
Supports of Deformation Strengthened Ni-Al Alloy. Russ J Electrochem 2011;47:488-93.

[94] Sadykov V, Mezentseva N, Usoltsev V, Smorygo O, Mikutski V, Marukovich A, Bobrenok O, Uvarov N. Metal Supported SOFC on the Gradient Permeable Metal Foam Substrate. Adv Mater Res 2010;123-125:1083-6.

[95] Solov'ev AA, Sochugov NS, Ionov IV, Kirdyashkin AI, Kitler VD, Maznoi AS, Maksimov YM, Sigfusson TI. Synthesis and investigation of porous Ni-Al substrates for solid-oxide fuel cells. Inorg Mater Appl Res 2013;4:431-7.

[96] Molin S, Gazda M, Jasinski P. High temperature oxidation of porous alloys for solid oxide fuel cell applications. Solid State Ionics 2010;181:1214-20.

[97] Venkatachalam V, Molin S, Chen M, Smirnov I, Larsson PO, Hendriksen PV, Bonanos N. Optimization of ferritic steel porous supports for protonic fuel cells working at $600^{\circ} \mathrm{C}$. Mater Sci Technol 2014:1231-40.

[98] Boccaccini D, Frandsen H, Sudireddy BR, Blennow P, Persson ÅH, Kwok K, Vang Hendriksen P. Creep behaviour of porous metal supports for solid oxide fuel cells. Int J Hydrogen Energy 2014;39:21569-21580.

[99] Esposito L, Boccaccini DN, Pucillo GP, Frandsen HL. Secondary creep of porous metal supports for solid oxide fuel cells by a CDM approach. Mater Sci Eng A 2017;691:155-61.

[100] Hiraiwa C, Tawarayama H, Ota H, Higashino T, Okuno K, Majima M. Long-term stability of Ni-Sn porous metals for cathode current collector in solid oxide fuel cells. Int J Hydrogen Energy 2017;42:12567-73.

[101] Fu XZ, Melnik J, Low QX, Luo JL, Chuang KT, Sanger AR, Yang QM. Surface modified Ni foam as current collector for syngas solid oxide fuel cells with perovskite anode catalyst. Int J Hydrogen Energy 2010;35:11180-7.

[102] Jung H, Bae K, Jang DY, Lee YH, Cha SW, Shim JH. Evaluation of porous platinum, nickel, and lanthanum strontium cobaltite as electrode materials for low-temperature solid oxide fuel cells. Int. J. Hydrogen Energy 2014;39:17828-35.

[103] Dong J, Cheng Z, Zha S, Liu M. Identification of nickel sulfides on Ni-YSZ cermet exposed to $\mathrm{H} 2$ fuel containing $\mathrm{H} 2 \mathrm{~S}$ using Raman spectroscopy. J Power Sources 2006;156:461-5.

[104] Gross MD, Vohs JM, Gorte RJ. Recent progress in SOFC anodes for direct utilization of hydrocarbons. J Mater Chem 2007;17:3071.

[105] Shaikh SPS, Muchtar A, Somalu MR. A review on the selection of anode materials for solid-oxide fuel cells. Renew Sustain Energy Rev 2015;51:1-8.

[106] Sun C, Hui R, Roller J. Cathode materials for solid oxide fuel cells: A review. J Solid State Electrochem 2010;14:1125-44. 
[107] Williford RE, Chick LA , Maupin GD, Simner SP, Stevenson JW. Diffusion Limitations in the Porous Anodes of SOFCs. J Electrochem Soc 2003;150:A1067.

[108] An J, Kim Y-B, Prinz FB. Ultra-thin platinum catalytic electrodes fabricated by atomic layer deposition. Phys Chem Chem Phys 2013;15:7520.

[109] Corbin SF, Clemmer RMC, Yang Q. Development and characterization of porous composites for solid oxide fuel cell anode conduction layers using ceramic-filled highly porous ni foam. J Am Ceram Soc 2009;92:331-7.

[110] Perry ML, Fuller TF. A Historical Perspective of Fuel Cell Technology in the 20th Century. J Electrochem Soc 2002;149:S59.

[111] Kamarudin MZF, Kamarudin SK, Masdar MS, Daud WRW. Review: Direct ethanol fuel cells. Int J Hydrogen Energy 2013;38:9438-53.

[112] Yang Y Lou, Liu XH, Hao MQ, Zhang PP. Performance of a low-cost direct glucose fuel cell with an anion-exchange membrane. Int J Hydrogen Energy 2015;40:1097984.

[113] Cao D, Gao Y, Wang G, Miao R, Liu Y. A direct NaBH4-H2O2 fuel cell using Ni foam supported Au nanoparticles as electrodes. Int J Hydrogen Energy 2010;35:80713.

[114] Merle G, Wessling M, Nijmeijer K. Anion exchange membranes for alkaline fuel cells: A review. J Memb Sci 2011;377:1-35.

[115] Blizanac BB, Ross PN, Markovic NM. Oxygen electroreduction on Ag(111): The pH effect. Electrochim Acta 2007;52:2264-71.

[116] Fujiwara N, Yamazaki S ichi, Siroma Z, Ioroi T, Senoh H, Yasuda K. Nonenzymatic glucose fuel cells with an anion exchange membrane as an electrolyte. Electrochem Commun 2009;11:390-2.

[117] Chen J, Zhao CX, Zhi MM, Wang K, Deng L, Xu G. Alkaline direct oxidation glucose fuel cell system using silver/nickel foams as electrodes. Electrochim Acta 2012;66:133-8.

[118] Spets JP, Kuosa MA, Kiros Y, Anttila T, Rantanen J, Lampinen MJ, Saari K. Enhancement of glucose electro-oxidation by an external electromagnetic field in direct-mode fuel cells. J Power Sources 2010;195:475-9.

[119] Bidault F, Brett DJL, Middleton PH, Brandon NP. Review of gas diffusion cathodes for alkaline fuel cells. J Power Sources 2009;187:39-48.

[120] Bidault F, Brett DJL, Middleton PH, Abson N, Brandon NP. A new application for nickel foam in alkaline fuel cells. Int J Hydrogen Energy 2009;34:6799-808. 
[121] Bidault F, Brett DJL, Middleton PH, Abson N, Brandon NP. An improved cathode for alkaline fuel cells. Int J Hydrogen Energy 2010;35:1783-8.

[122] Bidault F, Kucernak A. A novel cathode for alkaline fuel cells based on a porous silver membrane. J Power Sources 2010;195:2549-56.

[123] Bidault F, Kucernak A. Cathode development for alkaline fuel cells based on a porous silver membrane. J Power Sources 2011;196:4950-6.

[124] Li YS, Zhao TS. A high-performance integrated electrode for anion-exchange membrane direct ethanol fuel cells. Int J Hydrogen Energy 2011;36:7707-13.

[125] Zhao CX, Wang K, Yan $\mathrm{H}, \mathrm{Xu}$ Gu. Output current increase in alkaline glucose fuel cells. J. of the Electrochemical Society 2011;158:B1055-B1059

[126] Chen J, Zheng H, Kang J, Yang F, Cao Y, Xiang M. An alkaline direct oxidation glucose fuel cell using three-dimensional structural $\mathrm{Au} / \mathrm{Ni}$-foam as catalytic electrodes. RSC Adv 2017;7:3035-42.

[127] Ma J, Sahai Y. Effect of electrode fabrication method and substrate material on performance of alkaline fuel cells. Electrochem Commun 2013;30:63-6.

[128] $\mathrm{Li} \mathrm{Y}, \mathrm{He} \mathrm{Y}$. Layer reduction method for fabricating Pd-coated Ni foams as highperformance ethanol electrode for anion-exchange membrane fuel cells. RSC Adv 2014;4:16879.

[129] An L, Zhao TS, Chen R, Wu QX. A novel direct ethanol fuel cell with high power density. J Power Sources 2011;196:6219-22.

[130] An L, Zhao TS, Xu JB. A bi-functional cathode structure for alkaline-acid direct ethanol fuel cells. Int J Hydrogen Energy 2011;36:13089-95.

[131] Gu L, Luo N, Miley GH. Cathode electrocatalyst selection and deposition for a direct borohydride/hydrogen peroxide fuel cell. J Power Sources 2007;173:77-85.

[132] Li YS, Zhao TS. Understanding the performance degradation of anion-exchange membrane direct ethanol fuel cells. Int J Hydrogen Energy 2012;37:4413-21.

[133] Kucernak A, Bidault F, Smith G. Membrane electrode assemblies based on porous silver electrodes for alkaline anion exchange membrane fuel cells. Electrochim. Acta 2014;82:284-90.

[134] Millington B, Whipple V, Pollet BG. A novel method for preparing proton exchange membrane fuel cell electrodes by the ultrasonic-spray technique. J Power Sources 2011;196:8500-8.

[135] Tian ZQ, Lim SH, Poh CK, Tang Z, Xia Z, Luo Z, Shen PK, Chua D, Feng YP, Shen Z, Lin J. A highly order-structured membrane electrode assembly with vertically aligned carbon nanotubes for ultra-low Pt loading PEM fuel cells. Adv Energy Mater 2011;1:1205-14. 
[136] Wang YL, Zhao YQ, Xu CL, Zhao DD, Xu MW, Su ZX, Li HL. Improved performance of $\mathrm{Pd}$ electrocatalyst supported on three-dimensional nickel foam for direct ethanol fuel cells. J Power Sources 2010;195:6496-9.

[137] An L, Zhao TS. Transport phenomena in alkaline direct ethanol fuel cells for sustainable energy production. J Power Sources 2017;341:199-211.

[138] An L, Chai ZH, Zeng L, Tan P, Zhao TS. Mathematical modeling of alkaline direct ethanol fuel cells. Int J Hydrogen Energy 2013;38:14067-75.

[139] Yang WW, Lu MY, He YL. Performance study of an alkaline direct ethanol fuel cell with a reduced two-dimensional mass transport model. Int $\mathrm{J}$ Hydrogen Energy 2016;41:20693-708.

[140] Sopian K, Alghoul MA, Alfegi EM, Sulaiman MY, Musa EA. Evaluation of thermal efficiency of double-pass solar collector with porous-nonporous media. Renew Energy 2009;34:640-5.

[141] Naphon P. Effect of porous media on the performance of the double-pass flat plate solar air heater. Int Commun Heat Mass Transf 2005;32:140-50.

[142] Chen CC, Huang PC. Numerical study of heat transfer enhancement for a novel flatplate solar water collector using metal-foam blocks. Int J Heat Mass Transf 2012;55:6734-56.

[143] Chen Z, Gu M, Peng D. Heat transfer performance analysis of a solar flat-plate collector with an integrated metal foam porous structure filled with paraffin. Appl Therm Eng 2010;30:1967-73.

[144] Jouybari HJ, Saedodin S, Zamzamian A, Nimvari ME, Wongwises S. Effects of porous material and nanoparticles on the thermal performance of a flat plate solar collector: An experimental study. Renew Energy 2017;114:1407-18.

[145] He Q, Zeng S, Wang S. Experimental investigation on the efficiency of flat-plate solar collectors with nanofluids. Appl Therm Eng 2014;88:165-71.

[146] Chaji H, Ajabshirchi Y, Esmaeilzadeh E, Heris SZ, Hedayatizadeh M, Kahani M. Experimental study on thermal efficiency of flat plate solar collector using tio2/water nanofluid. Mod Appl Sci 2013;7:60-9.

[147] Moghadam AJ, Farzane-Gord M, Sajadi M, Hoseyn-Zadeh M. Effects of CuO/water nanofluid on the efficiency of a flat-plate solar collector. Exp Therm Fluid Sci 2014;58:9-14.

[148] Lim S, Kang Y, Lee H, Shin S. Design optimization of a tubular solar receiver with a porous medium. Appl Therm Eng 2014;62:566-72. 
[149] Reddy KS, Ravi Kumar K, Ajay CS. Experimental investigation of porous disc enhanced receiver for solar parabolic trough collector. Renew Energy 2015;77:30819.

[150] Baskar.P, Edison G, Ravikumar.T.S, Sathyamurthy R. Modeling, simulation and performance analysis of porous disc receiver for solar parabolic trough collector. Int $\mathrm{J}$ Sci Eng Res 2013;4:108-11.

[151] Becker M, Fend T, Hoffschmidt B, Pitz-Paal R, Reutter O, Stamatov V, Steven M, Trimis D. Theoretical and numerical investigation of flow stability in porous materials applied as volumetric solar receivers. Sol Energy 2006;80:1241-8.

[152] Wu Z, Caliot C, Bai F, Flamant G, Wang Z, Zhang J, Tian C. Experimental and numerical studies of the pressure drop in ceramic foams for volumetric solar receiver applications. Appl Energy 2010;87:504-13.

[153] Michailidis N, Stergioudi F, Omar H, Missirlis D, Vlahostergios Z, Tsipas S, Albanakis C, Granier B. Flow, thermal and structural application of Ni-foam as volumetric solar receiver. Sol Energy Mater Sol Cells 2013;109:185-91.

[154] Huang PC, Chen CC, Hwang HY. Thermal enhancement in a flat-plate solar water collector by flow pulsation and metal-foam blocks. Int $\mathrm{J}$ Heat Mass Transf 2013;61:696-720.

[155] Rabadi NJ, Mismar SA. Enhancing solar energy collection by using curved flow technology coupled with flow in porous media: An experimental study. Sol Energy 2003;75:261-8.

[156] Xu H, Gong L, Huang S, Xu M. Non-equilibrium heat transfer in metal-foam solar collector with no-slip boundary condition. Int J Heat Mass Transf 2014;76:357-65.

[157] Tian Y, Zhao CY. A review of solar collectors and thermal energy storage in solar thermal applications. Appl Energy 2013;104:538-53.

[158] Kasaeian A, Eshghi AT, Sameti M. A review on the applications of nanofluids in solar energy systems. Renew Sustain Energy Rev 2015;43:584-98.

[159] Pandey KM, Chaurasiya R. A review on analysis and development of solar flat plate collector. Renew Sustain Energy Rev 2017;67:641-50.

[160] Mesalhy O, Lafdi K, Elgafy A, Bowman K. Numerical study for enhancing the thermal conductivity of phase change material (PCM) storage using high thermal conductivity porous matrix. Energy Convers Manag 2005;46:847-67.

[161] Xiao X, Zhang P, Li M. Preparation and thermal characterization of paraffin/metal foam composite phase change material. Appl Energy 2013;112:1357-66.

[162] Chen Z, Gao D, Shi J. Experimental and numerical study on melting of phase change materials in metal foams at pore scale. Int J Heat Mass Transf 2014;72:646-55. 
[163] $\mathrm{Wu} \mathrm{ZG}$, Zhao CY. Experimental investigations of porous materials in high temperature thermal energy storage systems. Sol Energy 2011;85:1371-80.

[164] Zhao CY, Lu W, Tian Y. Heat transfer enhancement for thermal energy storage using metal foams embedded within phase change materials (PCMs). Sol Energy 2010;84:1402-12.

[165] Yang X, Meng X, Wang Z, Jin L, Zhang Q, Zhang Q, Lu T. Direct Numerical Simulation on Melting Phase Change Behavior in Open-cell Metal Foam. Energy Procedia 2017; 105:4254-9.

[166] Badenhorst H, Fox N, Mutalib A. The use of graphite foams for simultaneous collection and storage of concentrated solar energy. Carbon N Y 2016;99:17-25.

[167] Xu H, Sze JY, Romagnoli A, Py X. Selection of Phase Change Material for Thermal Energy Storage in Solar Air Conditioning Systems. Energy Procedia 2017;105:42818. 
(a)

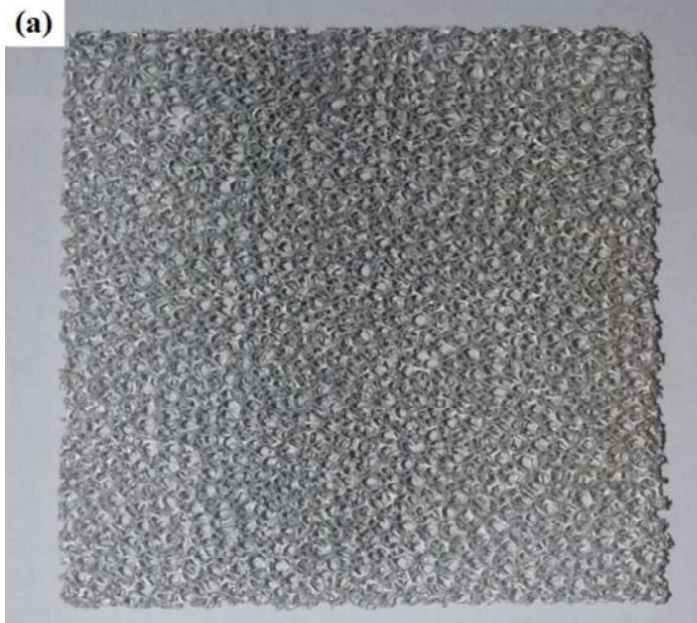

(b)

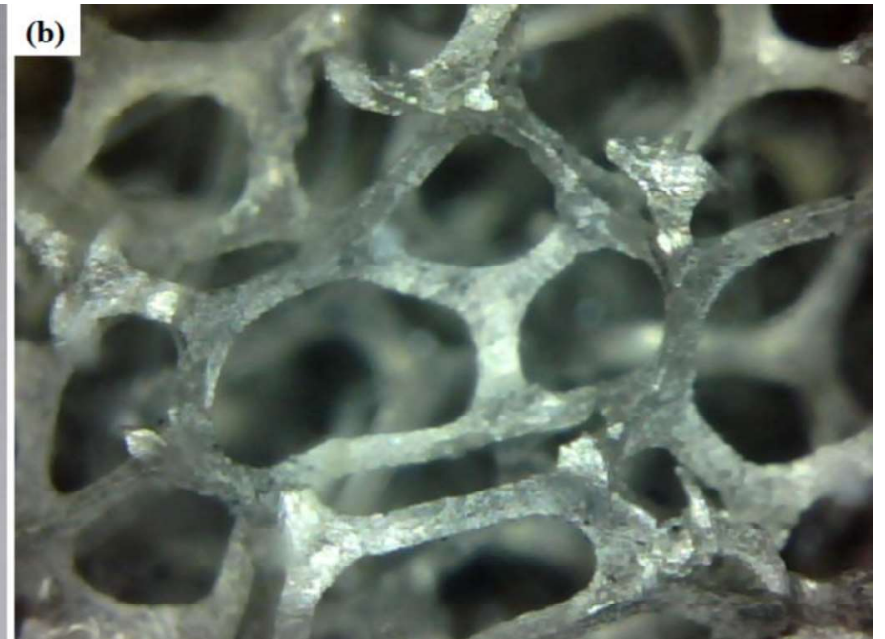

Fig. 1. a) Aluminium foam sample and b) close view of the aluminium foam structure [12]. 


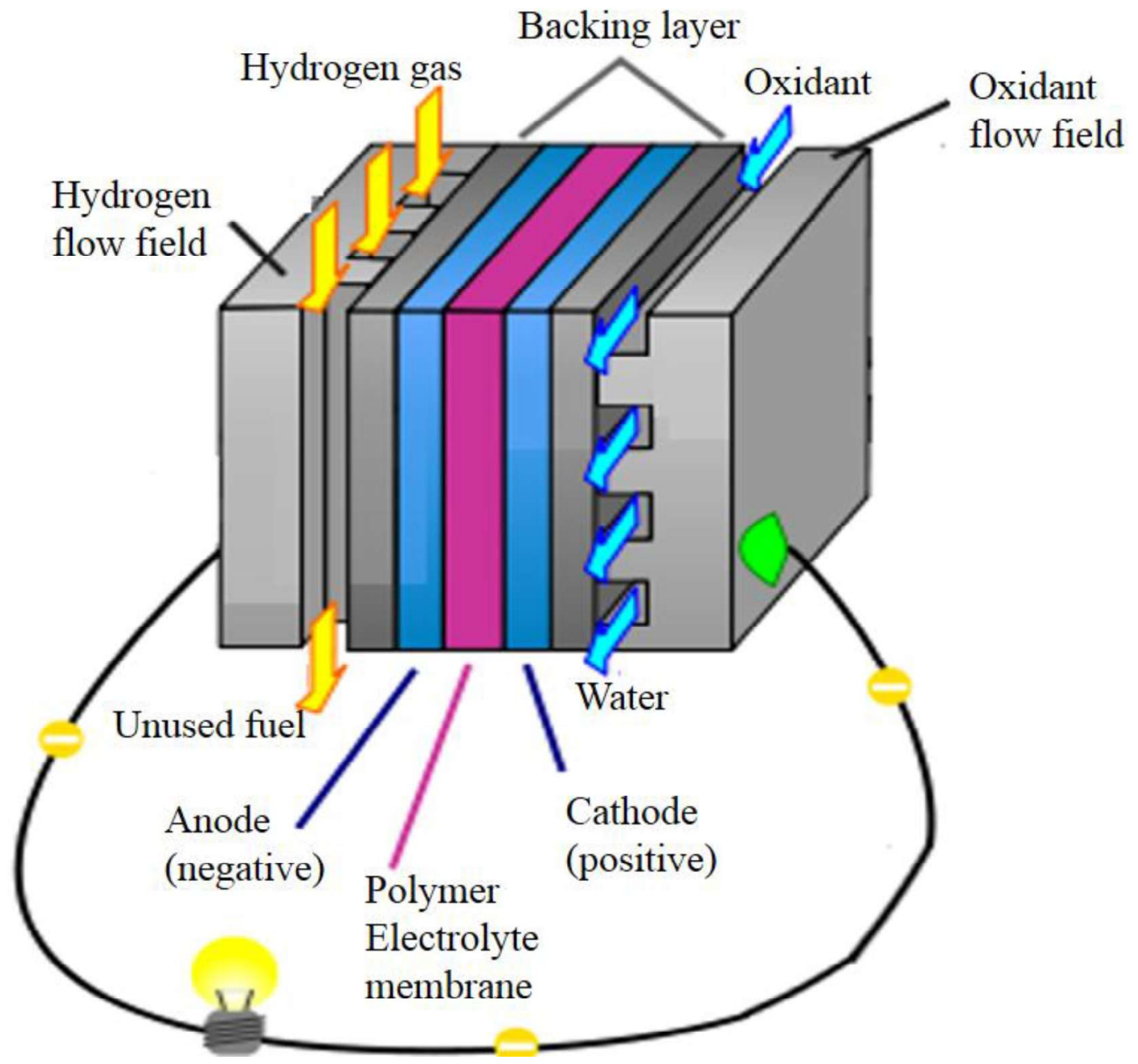

Fig. 2. Proton Exchange Membrane Fuel Cell design [15]. 


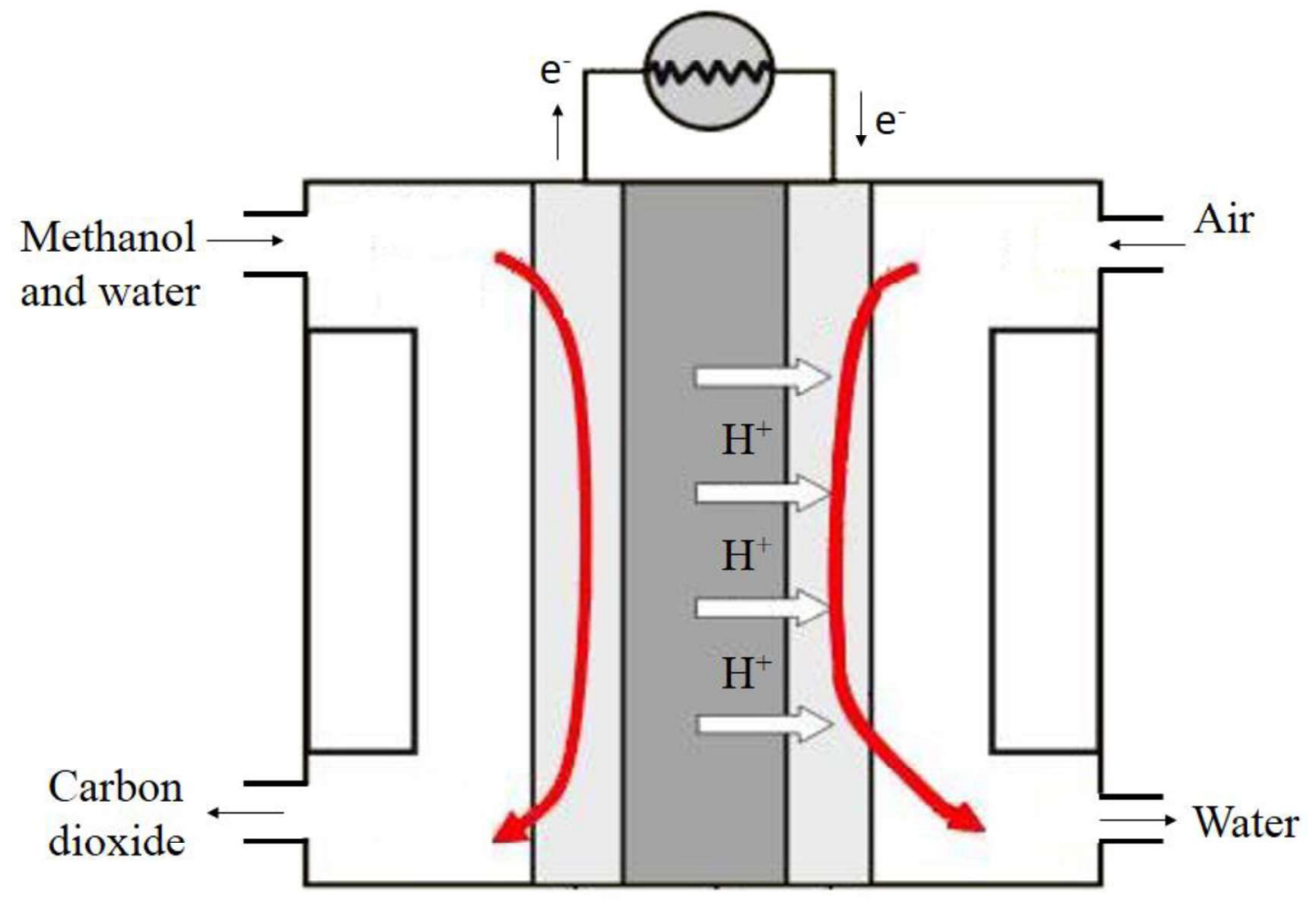

Fig. 3. Schematic diagram of a Direct Methanol Fuel Cell [40]. 


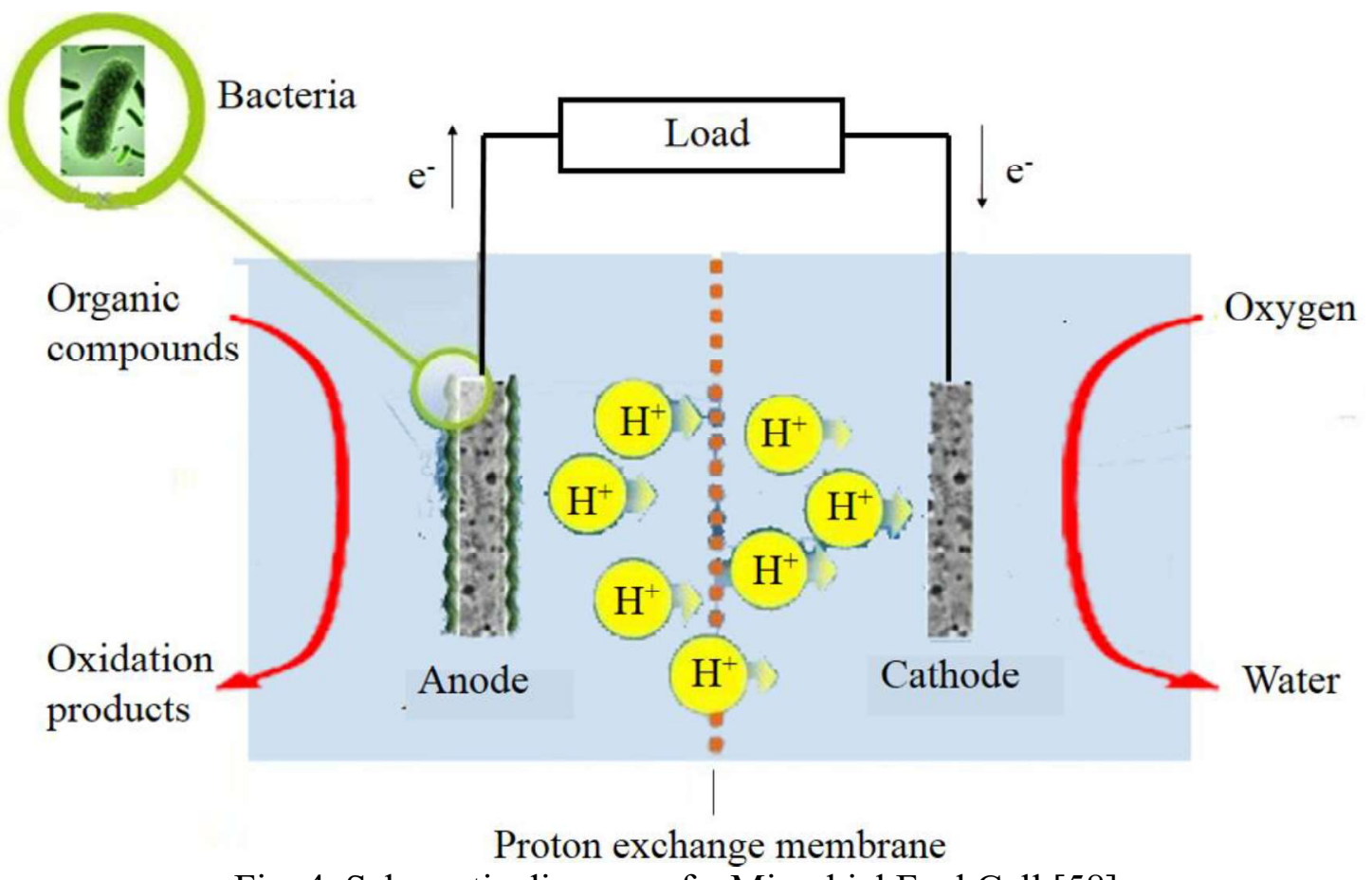

Fig. 4. Schematic diagram of a Microbial Fuel Cell [58]. 


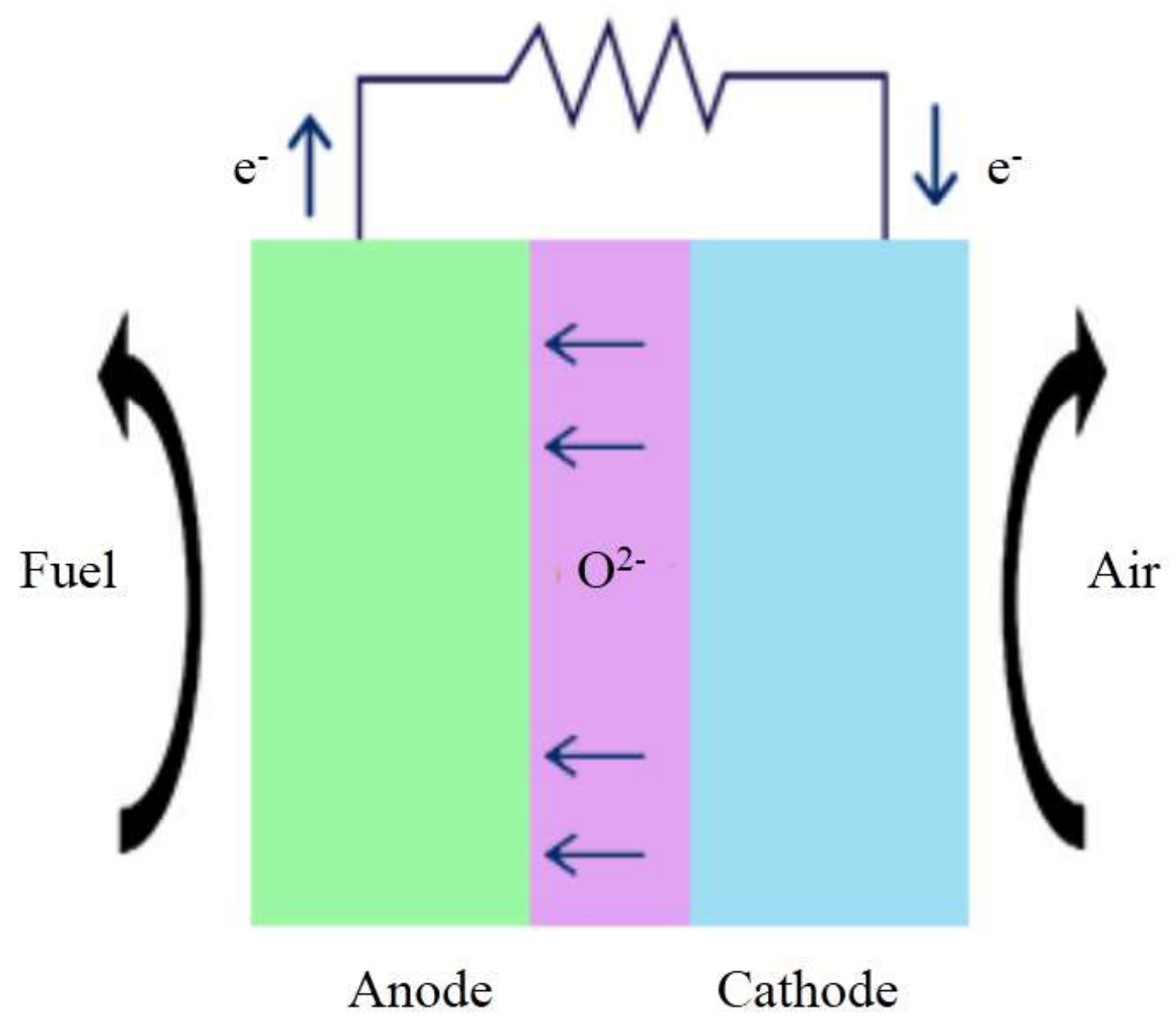

Fig. 5. Structure of a Solid Oxide Fuel Cell [78]. 


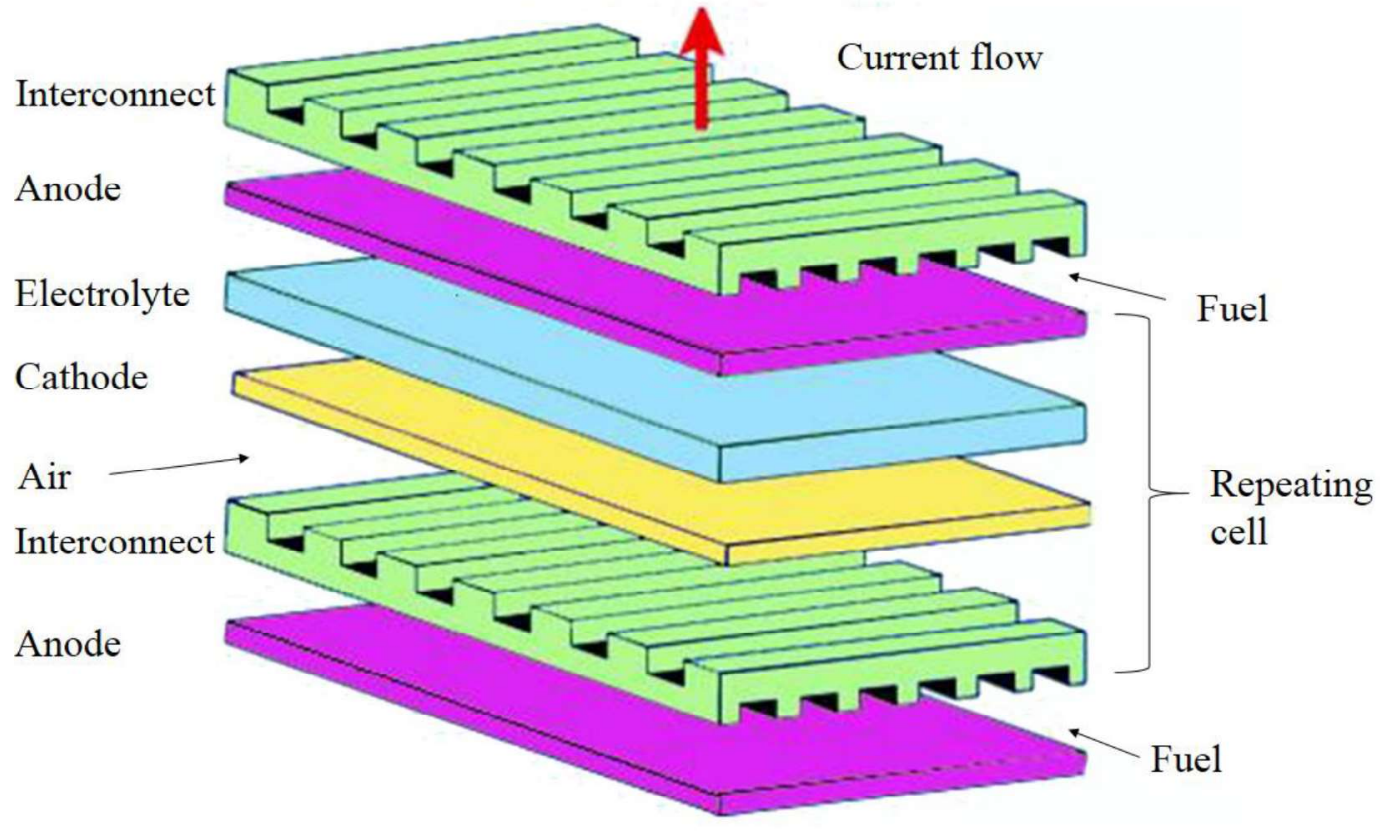

Fig. 6. Construction layout of the Solid Oxide Fuel Cell stack [80]. 


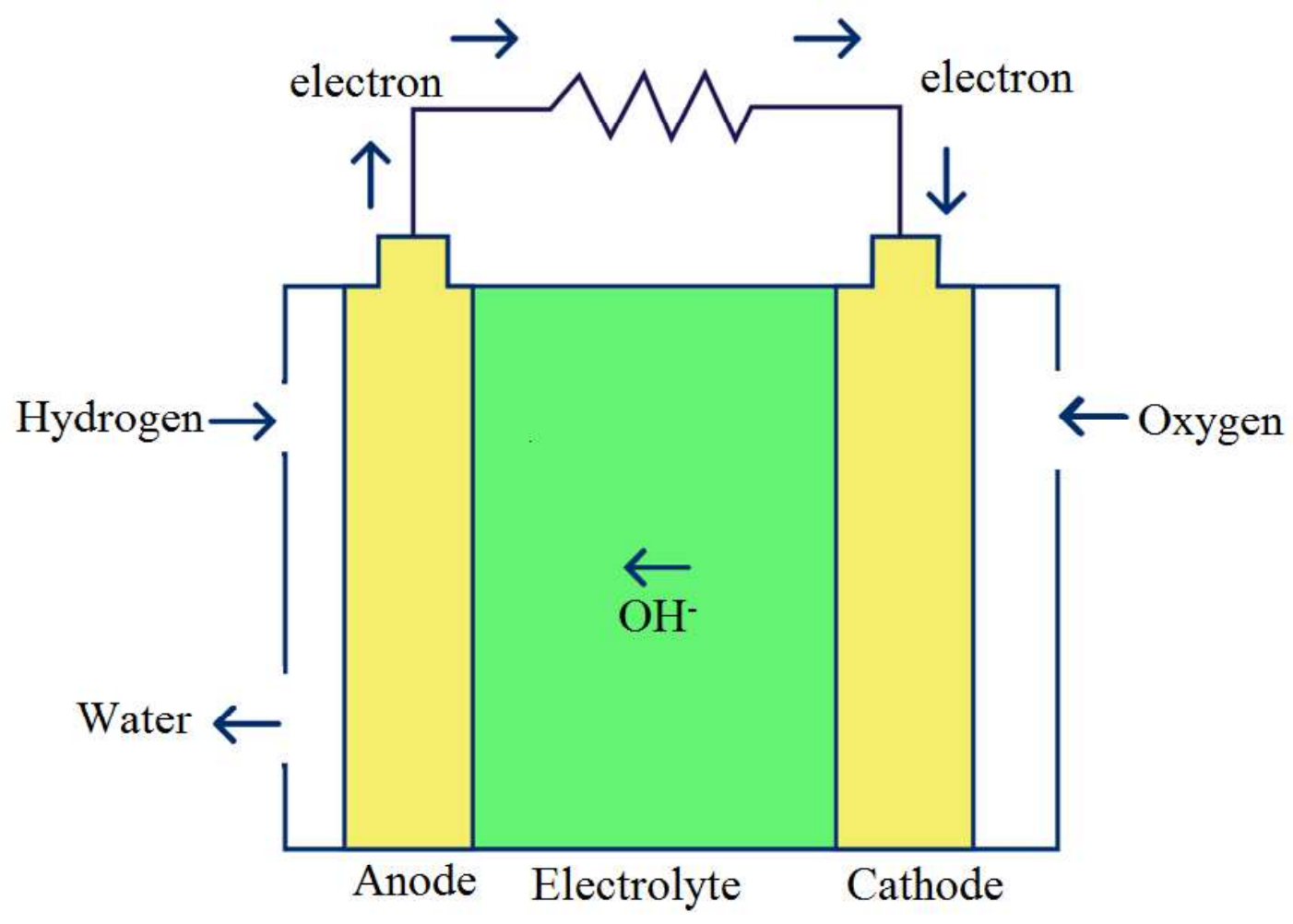

Fig. 7. Schematic diagram of an Alkaline Fuel Cell [40]. 


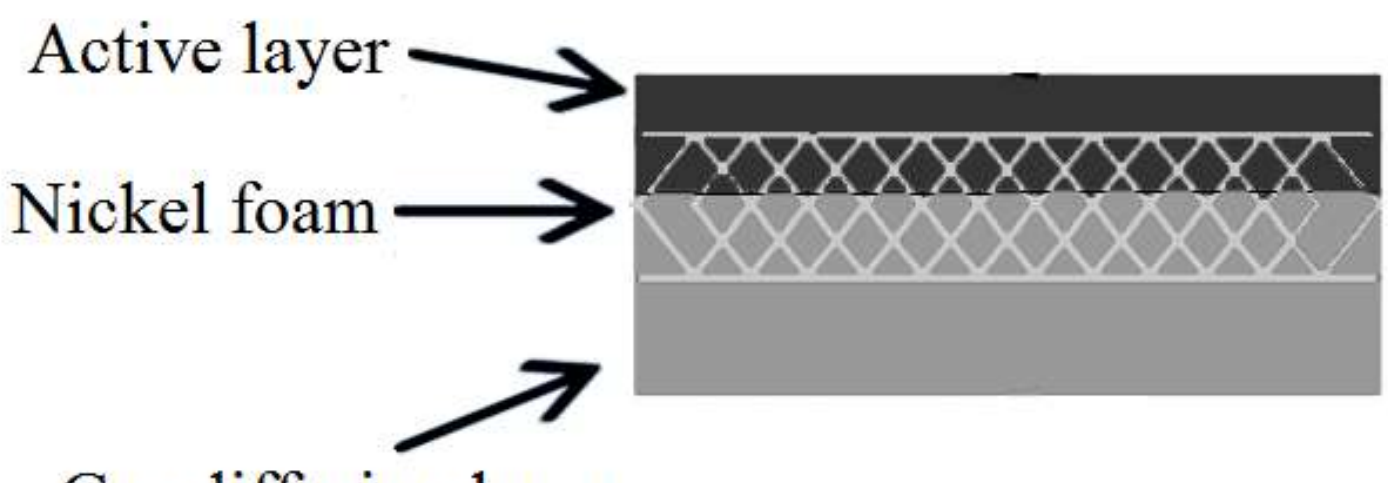

\section{Gas diffusion layer}

Fig. 8. Schematic diagram of an integrated cathode electrode [121]. 


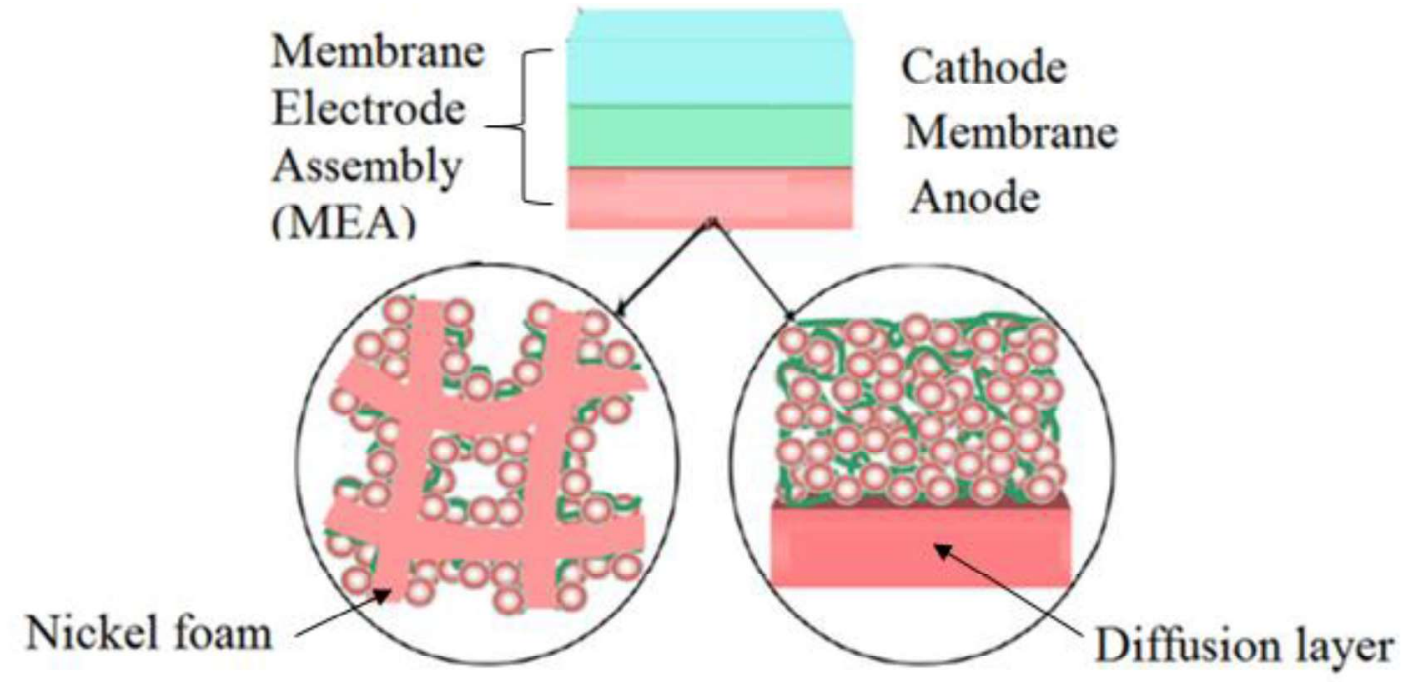

Fig. 9. Diagram of an anode structure: newly developed integrated anode electrode (left), conventional anode electrode (right) [124]. 


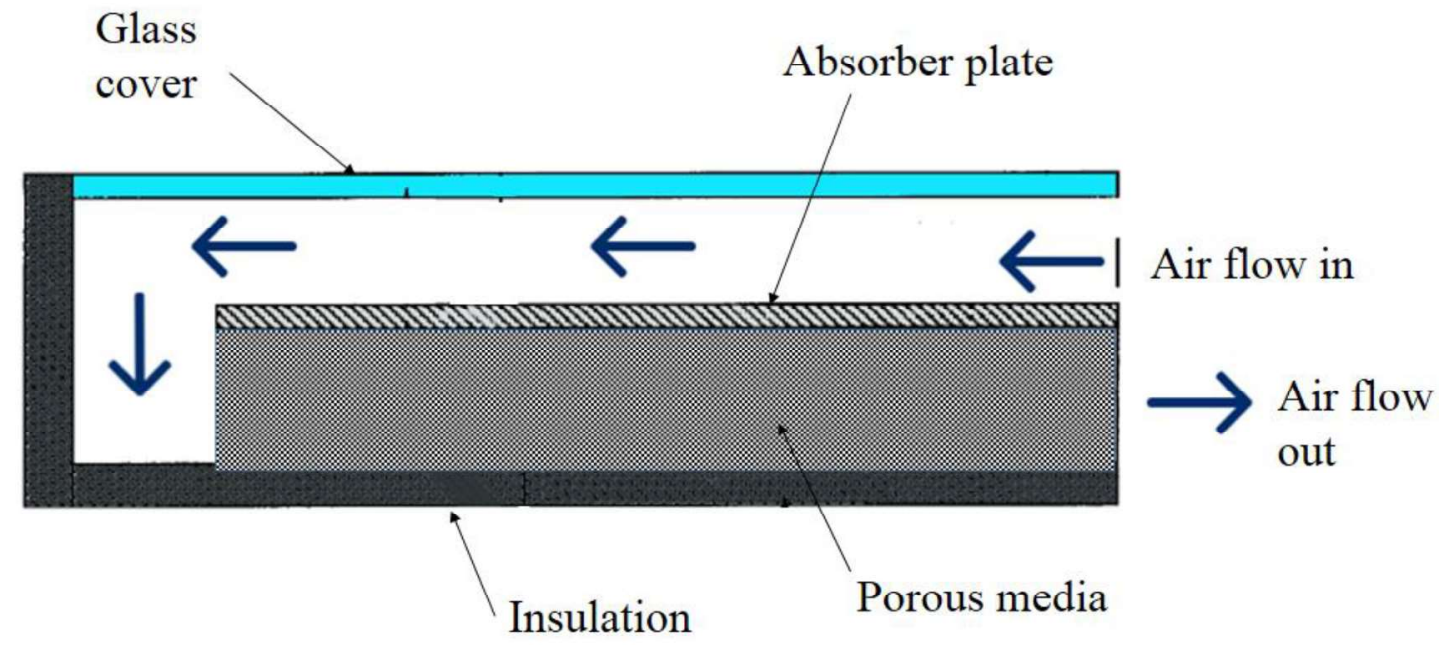

Fig. 10. Schematic diagram of a double-pass thermal solar collector with porous media in the second channel [8]. 
Metal Foam Block

¿Absorber Plate

Insulator

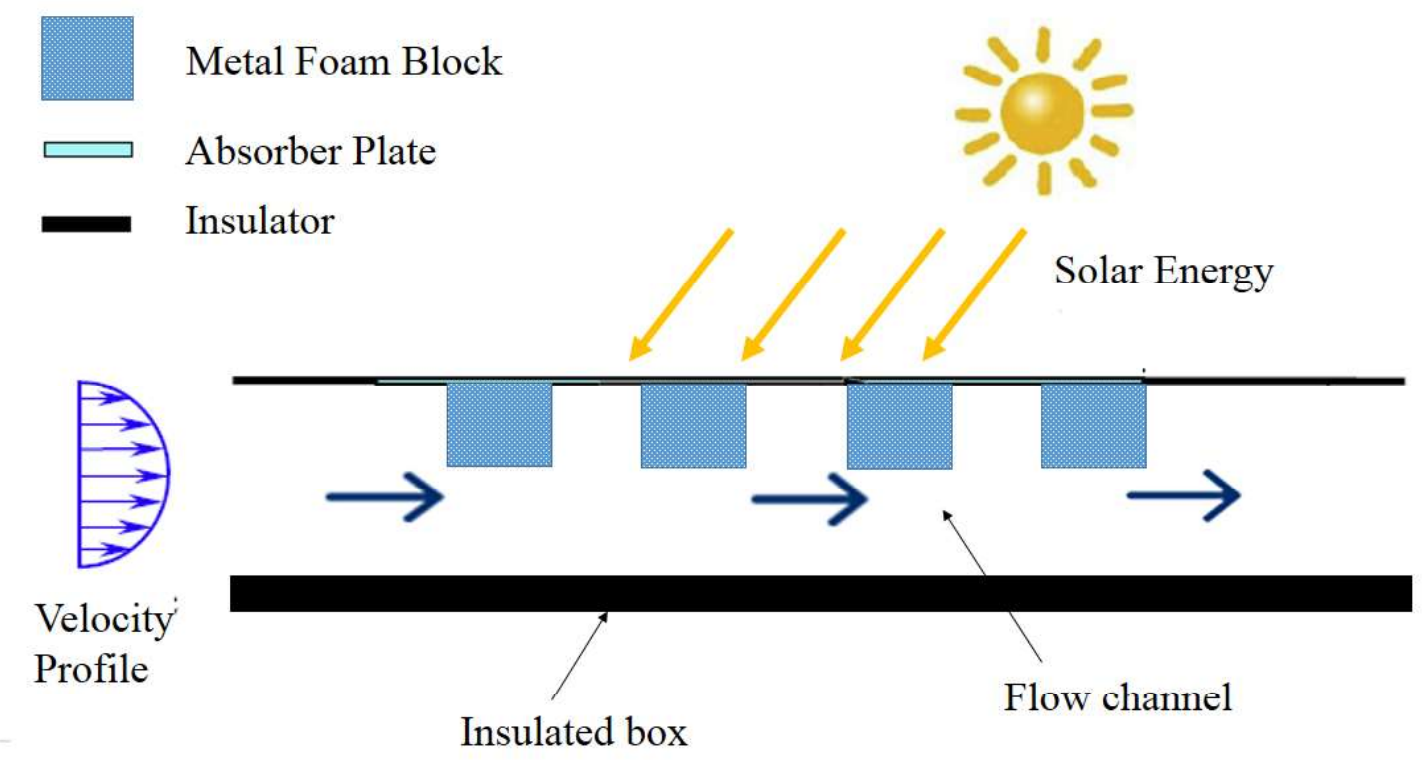

Fig. 11. Schematic diagram of a flat-plate solar collector [142]. 


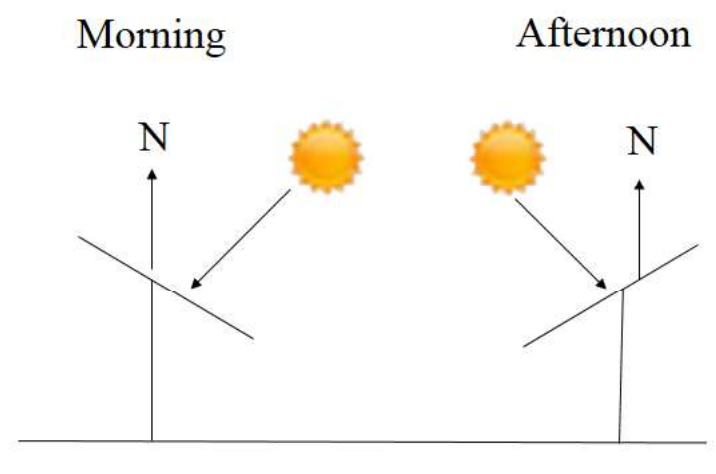

A

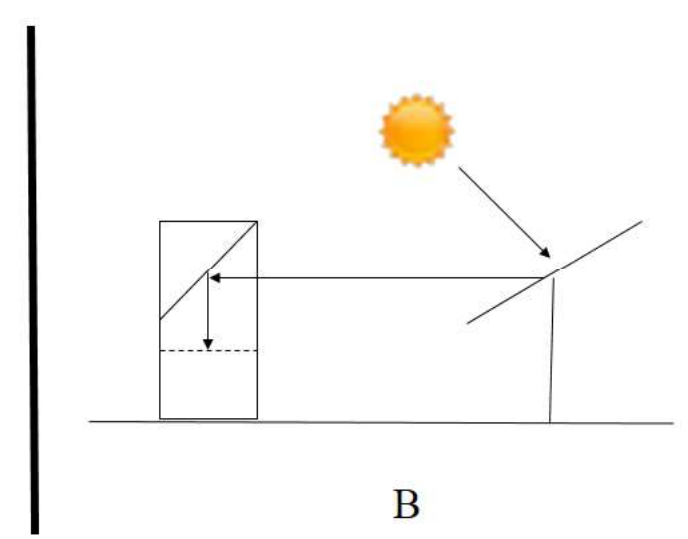

Fig. 12. Illustration of tracking system from morning to afternoon [166]. 
Table 1. Example of Microbes and its corresponding substrate [59].

Microbes

Substrate

Actinobacillus Succinogenes

Glucose

Escherichia Coli

Glucose, Sucrose

Clostridium Butyricum

Aeromonas Hydrophilia

Starch, Glucose, Lactate, Molasses

Desulfovibrio Desulfuricans

Acetate

Sucrose 
Table 2. Example of substrate with its corresponding the power density [60].

\begin{tabular}{lc}
\hline Substrates & Power produced in $\mathrm{mA} \cdot \mathrm{cm}^{-2}$ \\
\hline Lactate & 0.005 \\
1,2-Dichloroethane & 0.008 \\
Cysteine & 0.0186 \\
Ethanol & 0.025 \\
Propionate & 0.035 \\
Carboxymethyl cellulose & 0.05 \\
Azo dye with glucose & 0.09 \\
Phenol & 0.1 \\
Furfural & 0.17 \\
Sucrose & 0.19 \\
Sodium formate & 0.22 \\
Mannitol & 0.58 \\
Starch & 0.62 \\
Sorbitol & 0.62 \\
Arabitol & 0.68 \\
Glucose & 0.70 \\
Xylitol & 0.71 \\
Ribitol & 0.73 \\
Xylose & 0.74 \\
Galactitol & 0.78 \\
Acetate & 0.8 \\
Glucuronic acid & 1.18 \\
\hline
\end{tabular}




\section{Highlights}

- This article reviews the past research on metal foam in fuel cell and solar power systems.

- Metal foam applications on bipolar plates, electrodes and the gas diffusion layer in a fuel cell.

- Metal foam as a thermal management system in solar power systems.

- Barriers and future perspectives of metal foam applications in fuel cells and solar power systems. 